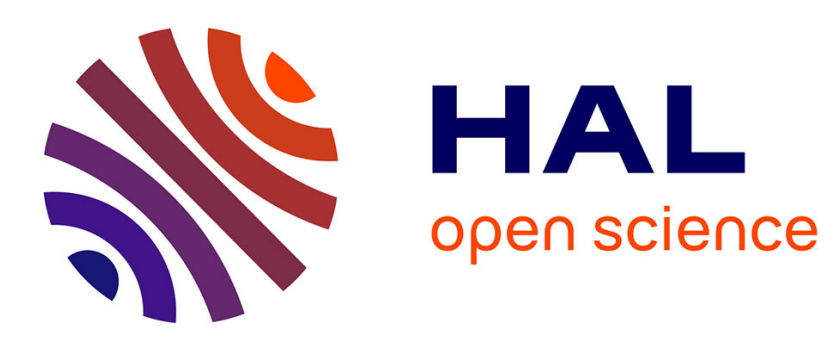

\title{
Elastic properties of anisotropic synthetic calcite-muscovite aggregates
}

Bjarne S. G. Almqvist, Luigi Burlini, David Mainprice, Ann M. Hirt

\section{To cite this version:}

Bjarne S. G. Almqvist, Luigi Burlini, David Mainprice, Ann M. Hirt. Elastic properties of anisotropic synthetic calcite-muscovite aggregates. Journal of Geophysical Research, 2010, 115, pp.B08203. 10.1029/2009JB006523 . hal-00512666

\section{HAL Id: hal-00512666 https://hal.science/hal-00512666}

Submitted on 30 Apr 2021

HAL is a multi-disciplinary open access archive for the deposit and dissemination of scientific research documents, whether they are published or not. The documents may come from teaching and research institutions in France or abroad, or from public or private research centers.
L'archive ouverte pluridisciplinaire HAL, est destinée au dépôt et à la diffusion de documents scientifiques de niveau recherche, publiés ou non, émanant des établissements d'enseignement et de recherche français ou étrangers, des laboratoires publics ou privés. 


\title{
Elastic properties of anisotropic synthetic calcite-muscovite aggregates
}

\author{
Bjarne S. G. Almqvist, ${ }^{1}$ Luigi Burlini, ${ }^{2}$ David Mainprice, ${ }^{3}$ and Ann M. Hirt ${ }^{1}$ \\ Received 8 April 2009; revised 17 February 2010; accepted 16 March 2010; published 7 August 2010.
}

[1] A set of synthetic aggregates, containing mixtures of calcite and muscovite, were compacted with varying uniaxial loads ranging from $20 \mathrm{MPa}$ up to $400 \mathrm{MPa}$. Their elastic properties have been measured using compressional and shear waves in confining hydrostatic pressures up to $475 \mathrm{MPa}$. Measured seismic velocities are shown to depend on 1) the ratio of calcite to muscovite, 2) the uniaxial load used during sample manufacturing, and 3) the porosity amount prior to velocity measurements. The matrix framework may also affect the seismic velocities, but this effect is not easily quantifiable. In general, measured seismic velocities decrease with increasing muscovite content and porosity. Elastic properties have been calculated based on texture measurements, which were obtained by neutron diffraction. The calculated velocities are based on the calcite and muscovite single crystal elastic tensors, their orientation distribution functions, and their modal fractions. A large discrepancy is apparent between calculated and measured velocities, where the former always overestimate the actual velocities. Shear waves display less of a difference between calculated and measured values, than do compressional waves, indicating that waves propagating by shearing are less affected by sample porosity and matrix framework. A better agreement between measured and calculated seismic velocities arises when the initial porosity is taken into account, using a differential effective medium model. Seismic anisotropy is evident from both measured and calculated velocities, and is low for samples containing pure calcite, but becomes prominent as the muscovite concentration increases. The intensity of anisotropy further depends on the uniaxial load used during sample compaction and the initial porosity.

Citation: Almqvist, B. S. G., L. Burlini, D. Mainprice, and A. M. Hirt (2010), Elastic properties of anisotropic synthetic calcite-muscovite aggregates, J. Geophys. Res., 115, B08203, doi:10.1029/2009JB006523.

\section{Introduction}

[2] Elastic properties of rock-forming minerals and rocks are deduced from seismic velocities and provide essential information for inferring the composition and structure of the Earth's interior. On a small scale, laboratory measurements provide information regarding the wave-propagation in rocks from the Earth's crust [e.g., Burlini and Fountain, 1993; Khazanehdari et al., 1998; Weiss et al., 1999; Mondol et al., 2007]. To compliment laboratory measurements, elastic properties of aggregates are commonly calculated when the volume fractions of the various phases are known, together with their elastic moduli, for example using Voigt's [1928] and Reuss's [1929] bounds.

[3] The propagation of seismic waves is affected, however, by the crystal-preferred orientation (CPO) of an

\footnotetext{
${ }^{1}$ Institute of Geophysics, ETH Zurich, Zurich, Switzerland.

${ }^{2}$ Geological Institute, ETH Zurich, Zurich, Switzerland.

${ }^{3}$ Géosciences Montpellier, Université Montpellier 2, Montpellier, France.

Copyright 2010 by the American Geophysical Union. 0148-0227/10/2009JB006523
}

aggregate of minerals and improvements in calculating the elastic properties can therefore be made by considering the anisotropic physical properties of the single-crystals together with their CPO, which are obtained through texture measurement methods [e.g., Mainprice, 1990, 2007; Mainprice and Humbert, 1994]. Modeling the elastic properties is often necessary when experimental data is lacking or not obtainable.

[4] Information on the elastic properties of micas and clay minerals are important since they make up a large fraction of the mineral composition in sedimentary basins, as well as in a variety of crustal settings, such as in fault gouges, and at the very top of the mantle. A wide range of values of elastic constants have been reported for phyllosilicates and clay minerals in the literature [e.g., Aleksandrov and Ryzhova, 1961a, 1961b; Vaughan and Guggenheim, 1986; Ellis et al., 1988], and recent work has demonstrated the need for a better understanding of elastic properties and their anisotropy in clay- and mica-rich rocks [e.g., Sayers, 2005; Cholach and Schmitt, 2006; Wong et al., 2008; Voltolini et al., 2009]. Seismic velocities measured for rocks containing abundant phyllosilicates or clays often deviate from the calculated seismic velocities based on intrinsic single-crystal 
elastic constants, due to the presence of micro-porosity and cracks. Cholach and Schmitt [2006] have suggested that the elastic properties of muscovite can serve as a good proxy for illite, since the single-crystal elastic constants of illite are not yet known. The single-crystal elastic properties of calcite have been studied in detail [e.g., Peselnick and Robie, 1963; Dandekar, 1968; Chen et al., 2001], as well as the elastic properties of carbonates in several geological settings [e.g., Rafavich et al., 1984; Wang et al., 1991; Anselmetti and Eberli, 1993; Wang, 1997; Khazanehdari et al., 1998; Burlini and Kunze, 2000; Verwer et al., 2008]. Results from these studies are of direct interest for reservoir geology, and for structural and tectonic studies since carbonates commonly accommodate plastic strain during deformation [e.g., Kennedy and White, 2001; Austin et al., 2008]. Calcite is interesting with respect to its texture and related physical properties (i.e., magnetic and seismic properties), which have been the subject of study in natural settings [e.g., Burlini et al., 1998; Khazanehdari et al., 1998; Leiss and Ullemeyer, 1999; Burlini and Kunze, 2000]. In addition, calcite is the predominant minerals in carbonate rocks, making up a large portion of oil-reservoir rocks.

[5] For this study seismic velocities are determined for a set of compacted calcite-muscovite aggregates described by Schmidt et al. [2008]. The composition of the samples ranges from the pure end-members of calcite and muscovite, with compaction pressures from 20-400 $\mathrm{MPa}$. Compressional $\left(V_{P}\right)$ and shear $\left(V_{S}\right)$ waves are measured to investigate how elastic properties depend on mineralogical composition, CPO of minerals and porosity. Seismic velocities are also calculated using calcite and muscovite texture data of the samples. The measured and calculated seismic velocities are compared and the differences that arise between the two data sets are discussed. The relationship of the magnetic properties to texture of these synthetic aggregates is addressed by Schmidt et al. [2009].

\section{Sample Preparation and Methods}

\subsection{Sample Preparation}

[6] Preparation of the calcite-muscovite aggregates and their texture is described in detail by Schmidt et al. [2008, 2009]. In summary the calcite and muscovite powders were mixed in different ratios, and subsequently compacted with uniaxial compression at room temperature (UCP) with applied loads ranging from $20 \mathrm{MPa}$ to $400 \mathrm{MPa}$. The starting material for calcite was obtained from Carrara marble that was reduced to gravel size fragments, and subsequently crushed with an agate mill and sieved to keep the fraction $\leq 100 \mu \mathrm{m}$. Similarly muscovite, obtained from three different sources, originally from pegmatitic crystals [Schmidt et al., 2008], was crushed in an agate mill and the $\leq 100 \mu \mathrm{m}$ sieved fraction was used. After cold-pressing the canisters were sealed and welded with a steel cap, and isostatically hot pressed at $\sim 670^{\circ} \mathrm{C}$ and $160 \mathrm{MPa}$ confining pressure $\left(\mathrm{P}_{\mathrm{C}}\right)$. The initial uniaxial pressing developed a transverse isotropic sample fabric with a foliation plane normal to the axis of compaction, which has been confirmed using X-ray and neutron diffraction texture measurements [Schmidt et al., 2008, 2009], as well as the anisotropy of magnetic susceptibility [Schmidt et al., 2009]. Calcite c-axes align parallel to the axis of compression. A weak CPO de- velops due to passive grain rotation at low pressures, so that the cleavage planes $\left(\begin{array}{lll}1 & 0-1 & 4\end{array}\right)$ are oriented roughly at $45^{\circ}$ to the compression axis [Schmidt et al., 2008]. Twinning was activated at higher uniaxial loads, which further strengthened the CPO of calcite c-axes, with a-axes of calcite dispersed randomly in the plane of foliation. Muscovite also display c-axes maxima parallel to the axis of compression, resulting from passive grain rotation, in which basal planes orient preferably normal to the compression axis. It should be noted however, that muscovite does not have perfectly hexagonal symmetry, but rather is monoclinic with the angle between unit cell axes $a$ and $c$ being slightly greater than $90^{\circ}$ $\left(\beta \sim 95.5-95.8^{\circ}\right)$. Details on the grain-sizes for calcite and muscovite subsequent to hot isostatic pressing are given in Figure 4 of Schmidt et al. [2008]. On average, for all samples, the calcite grain-size is less than $10 \mu \mathrm{m}$ after the final step of sample preparation [cf., Schmidt et al., 2008, Table 2].

[7] Cores were drilled along the axis of compression for each sample, and when possible perpendicular to this axis, i.e., normal to the compression axis. Specimens that were drilled parallel to the cylinder axis were $25.4 \mathrm{~mm}$ in diameter, whereas specimens drilled normal to the cylinder axis have $22 \mathrm{~mm}$ diameter (Figure 1). Core lengths varied between circa $20 \mathrm{~mm}$ to $38 \mathrm{~mm}$. A total of 21 cores were extracted parallel to the axis of compression and 8 cores were drilled normal to the compression axis, and used to measure acoustic wave-velocities. Specimens with a range of different calcite-muscovite ratios were obtained in both orientations (5-70\% muscovite content) and their $V_{P}$ and $V_{S}$ could be compared in order to determine the effect of preferred orientations of crystals and pore-space on wave propagation. Specimens were dried in an oven for at least $24 \mathrm{~h}$, at temperatures of $50-70^{\circ} \mathrm{C}$, prior to any experiments.

[8] Densities were determined by measuring the volume and mass of each individual specimen. The total porosity $(\varphi)$ was determined by comparing the specimen density with the single crystal densities of calcite, $\rho=2.71 \mathrm{~g} / \mathrm{cm}^{3}$, and muscovite, $\rho=2.82 \mathrm{~g} / \mathrm{cm}^{3}$ [Schmidt et al., 2008]. The propagated error of this method, for determining the total porosity is less than $2 \%$.

\subsection{Acoustic Velocity Measurements and Determination of Seismic Anisotropy}

[9] The velocities for compressional $\left(\mathrm{V}_{\mathrm{P}}\right)$ and shear waves with two polarizations (fast and slow shear waves, $\mathrm{V}_{\mathrm{S} 1}$ and $\mathrm{V}_{\mathrm{S} 2}$, respectively) were measured in a Paterson gasmedium, high-pressure apparatus, specifically modified for physical properties measurements at large confining pressures (Figures 2a and 2b). Measurements were performed at ultrasonic frequencies $(1 \mathrm{MHz})$, using ceramic transducers. The transducer assembly was jacketed with copper. In the case of short specimens, when the cores were less than $25 \mathrm{~mm}$ long, a zirconia spacer was added to provide the additional length needed for the column. The longer wavetravel times produced by the zircon spacer were later subtracted to obtain the actual velocity of the specimen. $V_{P}$ and $\mathrm{V}_{\mathrm{S}}$ were measured at increasing $\mathrm{P}_{\mathrm{C}}$, in intervals of $\sim 50 \mathrm{MPa}$ to a final $\mathrm{P}_{\mathrm{C}}$ of $300-475 \mathrm{MPa}$, in order to minimize the effect of porosity and cracks within a specimen (e.g., Figure 2c). Dry pores have been shown to affect the $V_{P}$ and $V_{S}$ significantly. It is generally accepted that most pores and cracks 


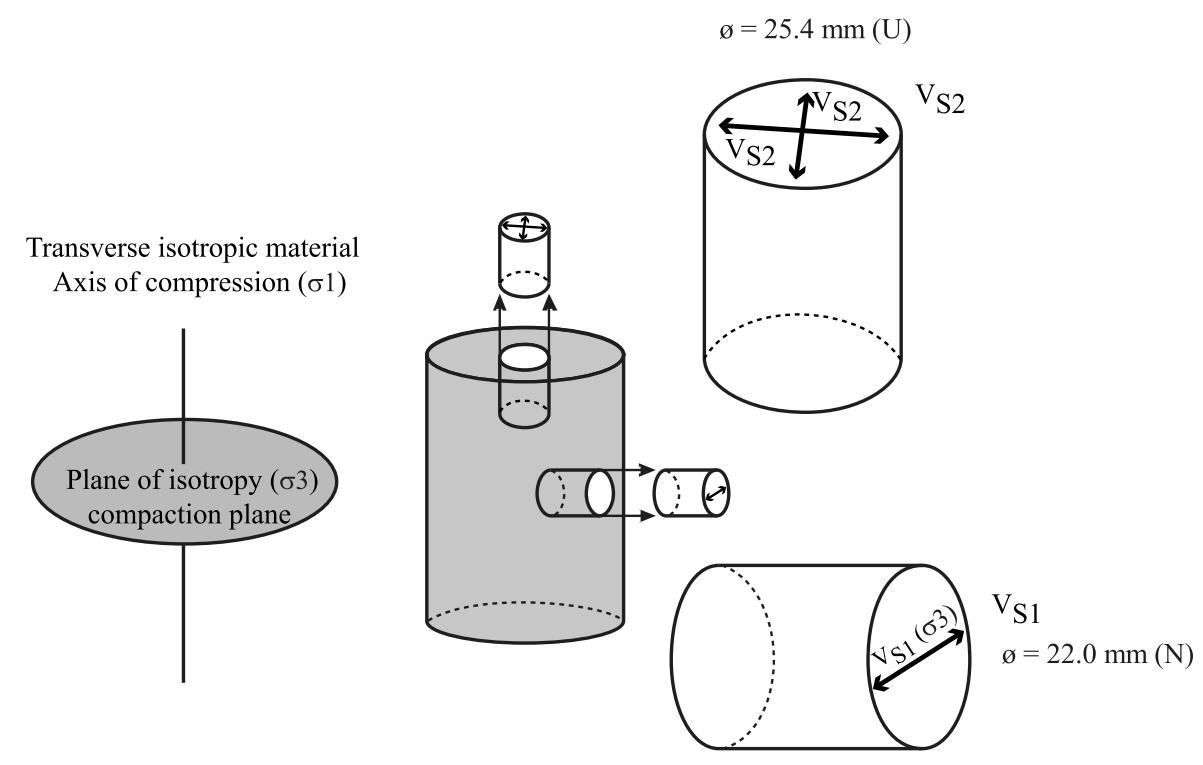

Figure 1. Illustration of the drilling scheme of cores for the synthetic samples, in which the axis of UCP load is indicated by $\sigma_{1}$, and the foliation plane develops perpendicular to the applied load, where the applied stress is least $\left(\sigma_{3}\right)$. The letter "U" refers to samples drilled with their long-axes parallel to the axis of compaction, whereas " $\mathrm{N}$ " refers to samples drilled normal to the axis of compaction. The enlarged images of the drill cores illustrate the polarization of shear waves with respect to the axis of compression $\left(\mathrm{V}_{\mathrm{S} 2}\right)$ and in the plane of compaction $\left(\mathrm{V}_{\mathrm{S} 1}\right)$.

close between $\mathrm{P}_{\mathrm{C}} \mathrm{s}$ of 100-250 MPa [Birch, 1960; Burlini and Kunze, 2000; Kern, 1990; Wepfer and Christensen, 1991], after which $V_{P}$ and $V_{S}$ increase due to compression of the mineral structures. One of the important factors controlling the closure pressure of a dry crack is its geometry. Thin cracks with large aspect ratios generally close at low pressures ( $\leq 100 \mathrm{MPa}$ [Walsh, 1965; Takanashi et al., 2001]), whereas spherical pores can remain open at pressures $>200 \mathrm{MPa}$ [Nur and Simmons, 1969]. Hysteresis is observed for velocities when $\mathrm{P}_{\mathrm{C}}$ is reduced to room pressure, due to some porous spaces and cracks that do not reopen. In order to obtain a representative measure of the $\mathrm{P}$ - and S-wave velocities such that the influence of porosity is minimized, a linear regression is fitted to the velocity measurements at high pressures where the increase in velocity is close to linear (Figure 2c [Burlini and Fountain, 1993]). The zero pressure intercept in Figure 2c, representing room pressure, is referred to as $\mathrm{V}_{\mathrm{P} 0}$ and $\mathrm{V}_{\mathrm{S} 0}$, for the compressional and shear waves, respectively, and represents the material without (or reduced) porosity. Error boundaries for the linear regression at room pressure are estimated by calculating the fiducial limits of the high-pressure data points used for the regression [Cheeney, 1983]. In the case of compressional waves the amount of anisotropy $\left(\mathrm{AV}_{\mathrm{P}}\right)$ was determined by $\mathrm{AV}_{\mathrm{P}}=2\left(\mathrm{~V}_{\mathrm{Pmax}}-\right.$ $\left.\mathrm{V}_{\text {Pmin }}\right) /\left(\mathrm{V}_{\text {Pmax }}+\mathrm{V}_{\text {Pmin }}\right)$, where $\mathrm{V}_{\text {Pmax }}$ is the highest velocity measured for a specimen and $V_{P \min }$ is the lowest velocity.

\subsection{Calculation of Seismic Velocities}

[10] To calculate the seismic velocities we use texture measurement data for calcite and muscovite aggregates, which were obtained by measurements of neutron diffraction pole figures at the FRJ-2 research reactor of the Forschungszentrum Jülich, Germany [Schmidt et al., 2009]. From the pole figures it is possible to compute the orien- tation distribution functions (ODF) for calcite and muscovite [Mainprice et al., 1993], using a spherical harmonic series expansion, truncated at degree 12. A summary of the pole figures used to compute the ODF for muscovite is provided in Figure 3. Note that four unique pole figures were available for the calculation of the muscovite ODF ( $\begin{array}{lllll}0 & 0 & 4,0 & 0 & 6 \text {, }\end{array}$ $0010),\left(\begin{array}{lll}1 & 1 & 0\end{array}\right),\left(\begin{array}{lll}1 & 1 & 6\end{array}\right)$ and $\left(\begin{array}{lll}1 & 3 & 5\end{array}\right)$, which are too few for the inversion considering its monoclinic symmetry [Bunge, 1982; Lapierre et al., 1996], and therefore we assume a hexagonal symmetry for muscovite.

[11] The method used to calculate the seismic velocities from the ODF is described by Mainprice et al. [1993] and Lapierre et al. [1996], using software originally developed by Casey [1981] and Mainprice [1990]. Single-crystal elastic constants used in the seismic velocity calculations were obtained from Dandekar [1968] and Chen et al. [2001] for calcite, and Vaughan and Guggenheim [1986] for muscovite. The model provides the velocities for P- and S-waves, their anisotropy, as well as polarization planes for the horizontally polarized S-waves and contours of the two S-waves. P- and S-waves were calculated with the VoigtReuss-Hill estimate (VRH [Hill, 1952]; the arithmetic mean of the Voigt upper bound [Voigt, 1928] and Reuss lower bound [Reuss, 1929]). The VRH results are presented and used for calculation of seismic velocities because this average is commonly close to actual measured velocities [Mainprice, 2007] and does not display a large difference with respect to the geometric mean averaging scheme [Mainprice and Humbert, 1994]. $\mathrm{V}_{\mathrm{P}}$ anisotropy for the calculated seismic velocities is described as in Section 2.2. Shear wave splitting $\left(\mathrm{dV}_{\mathrm{S}}\right)$ was determined by calculating the difference between the fast $\left(\mathrm{V}_{\mathrm{S} 1}\right)$ and the slow $\left(\mathrm{V}_{\mathrm{S} 2}\right) \mathrm{S}$-waves along a specific sample axis, such as parallel to the axis of uniaxial 

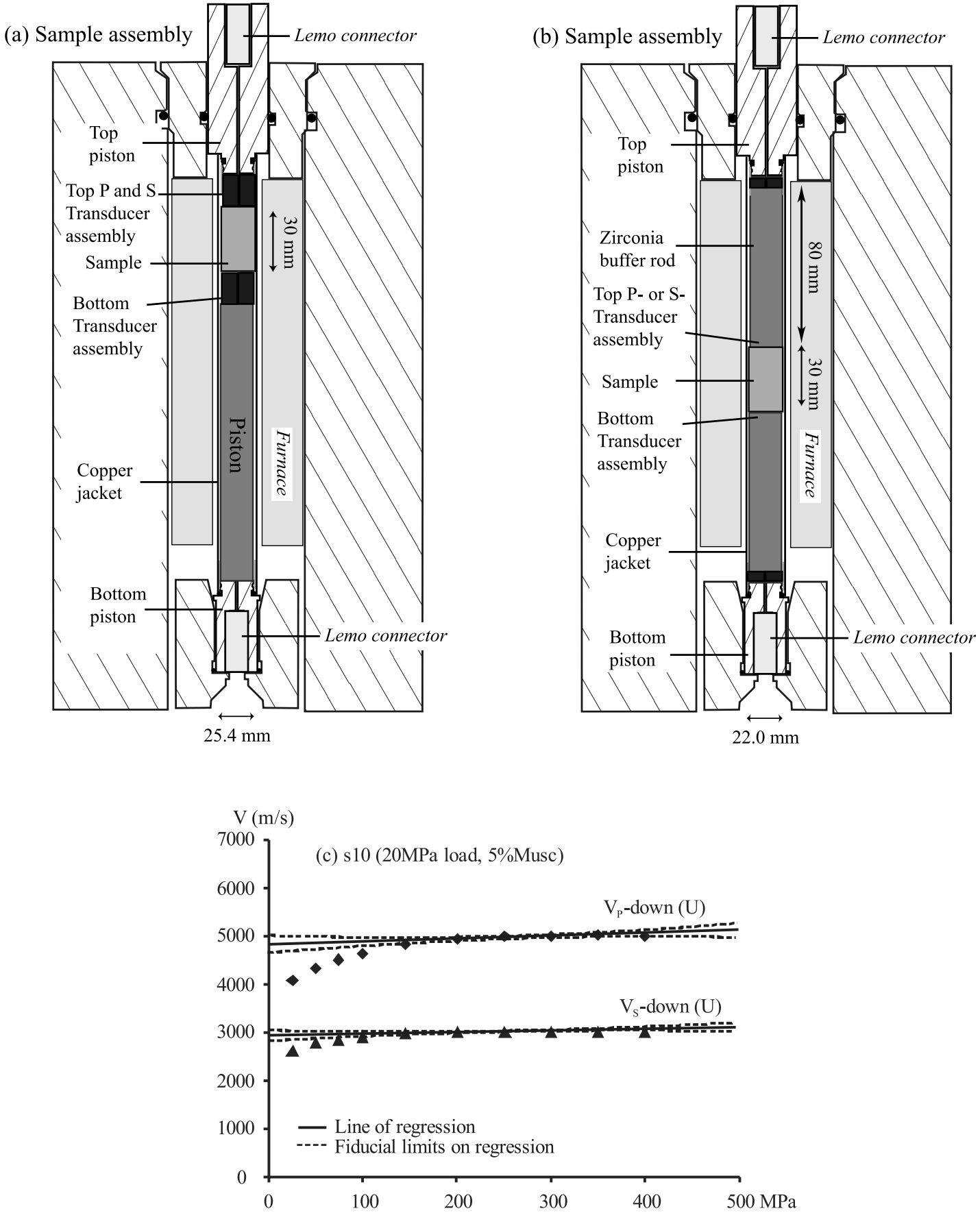

Figure 2. Schematic of sample assembly setup in the Paterson pressure vessel for (a) the $25.4 \mathrm{~mm}$ diameter sample assembly and (b) the $22.0 \mathrm{~mm}$ sample assembly; (c) example of how $\mathrm{V}_{\mathrm{P}}$ and $\mathrm{V}_{\mathrm{S}}$ were determined from the linear regression of high $\mathrm{P}_{\mathrm{C}}$ part (solid line) of the velocity-pressure curve, with fiducial limits (dashed line) of the linear regression.

compression, or in the plane normal to the compression axis (e.g., $\mathrm{dV}_{\mathrm{S}}=\mathrm{V}_{\mathrm{S} 1}-\mathrm{V}_{\mathrm{S} 2}$ ).

\section{Laboratory Results}

\subsection{Porosity and Density}

[12] Total porosity of the samples ranges from $3.5 \%$ to 24.5\% (Table 1 [Schmidt et al., 2008]). Most samples display increased porosity as the volume percentage of mus- covite increases with the exception of samples containing $100 \%$ muscovite, which display noticeably lower porosities than the overall trend [cf., Schmidt et al., 2008, Figure 1]. The applied load used during compaction reduces the amount of porosity and samples compressed with $20 \mathrm{MPa}$ uniaxial load typically have higher porosities, by a few percent, than samples compressed with greater loads. Porosities were also measured after velocity experiments had been performed in a $\mathrm{P}_{\mathrm{C}}$ of $300-475 \mathrm{MPa}$, and show a 
Equal Angle Stereogram : Muscovite Pole Figures

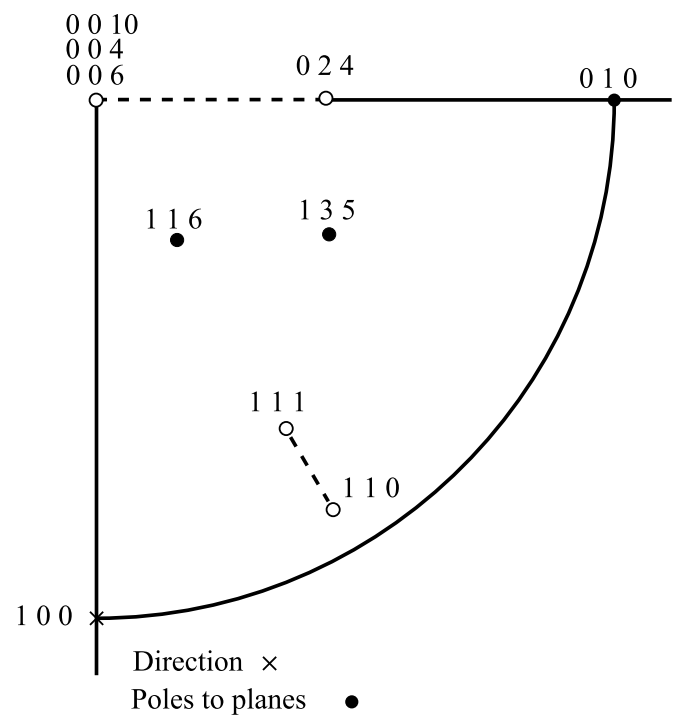

Figure 3. Pole figures used to compute the ODF for muscovite, shown on an upper hemisphere equal angle stereogram. The pole figures used for calculation of the ODF are $(004,006,0010),(110),(116)$ and $(135)$. Note that [100] direction was not measured.

decrease for all specimens of $\sim 1-2 \%$ relative to the porosities measured prior to the experiment.

[13] Sample densities $(\rho)$ are related to the amount of porosity of the samples (Figure 4). With the exception of two samples that leaked during hot isostatic pressing

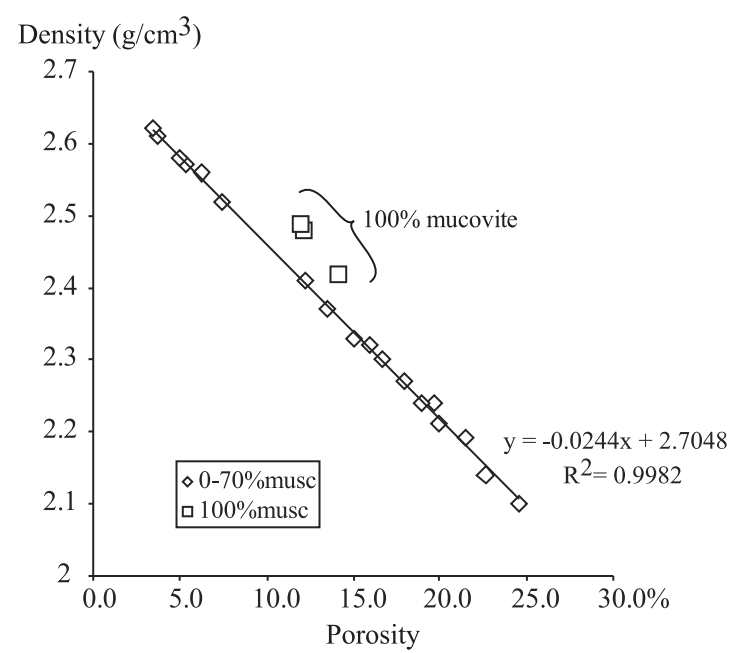

Figure 4. The calculated porosity in which the solid line is a linear fit to the data, excluding the three data points for samples containing $100 \%$ muscovite.

[Schmidt et al., 2008], which led to increased porosities, all samples with muscovite contents $\leq 70 \%$ display a linear trend. The projected density at $0 \%$ porosity is $2.70 \mathrm{~g} \mathrm{~cm}^{-3}$, which is close to the density of single crystal calcite $(\rho=$ $\left.2.71 \mathrm{~g} / \mathrm{cm}^{3}\right)$. The pure muscovite samples are slightly displaced with respect to the other samples but nearly parallel, where $\rho(100 \%$ muscovite $)=-0.031 \varphi+2.86$. Although the latter trend is based on only three specimens the density deviates clearly from the other samples. The projected intercept at $0 \%$ porosity is $2.86 \mathrm{~g} / \mathrm{cm}^{3}$, which is close to the

Table 1. Measured Seismic Velocities With the Standard Deviations and Ratio $\mathrm{V}_{\mathrm{P} 0} / \mathrm{V}_{\mathrm{S} 0}{ }^{\mathrm{a}}$

\begin{tabular}{|c|c|c|c|c|c|c|c|c|c|c|c|}
\hline Sample & $\mathrm{Mu}(\%)$ & Load (MPa) & $\rho\left(\mathrm{g} / \mathrm{cm}^{3}\right)$ & $\varphi(\%)$ & $\mathrm{V}_{\mathrm{P} 0}(\mathrm{~m} / \mathrm{s})$ & $\mathrm{V}_{\mathrm{P} 0} \pm 2 \sigma$ & $\mathrm{V}_{\mathrm{P} 400}(\mathrm{~m} / \mathrm{s})$ & $\mathrm{V}_{\mathrm{S} 0}(\mathrm{~m} / \mathrm{s})$ & $\mathrm{V}_{\mathrm{S} 0} \pm 2 \sigma$ & $\mathrm{V}_{\mathrm{S} 400}(\mathrm{~m} / \mathrm{s})$ & $\mathrm{V}_{\mathrm{P} 0} / \mathrm{V}_{\mathrm{S} 0}$ \\
\hline $0-20$ & 0 & 20 & 2.61 & 3.7 & 5463 & 549 & 6223 & 3021 & 137 & 3191 & 1.81 \\
\hline $0-100$ & 0 & 100 & 2.62 & 3.5 & 5225 & 386 & 5745 & 2990 & 88 & 3091 & 1.75 \\
\hline $5-40$ & 5 & 40 & 2.57 & 5.4 & 5363 & 104 & 5483 & 2978 & 35 & 3018 & 1.80 \\
\hline $5-40 \mathrm{~N}$ & 5 & 40 & 2.57 & 5.4 & 5528 & 119 & 6572 & & & 3286 & \\
\hline $5-200$ & 5 & 200 & 2.56 & 6.3 & 5325 & 327 & 5461 & 2963 & 45 & 2999 & 1.80 \\
\hline $5-400$ & 5 & 400 & 2.58 & 5.0 & 4938 & 338 & 5418 & 2905 & 85 & 3000 & 1.70 \\
\hline $5-400 \mathrm{~N}$ & 5 & 400 & 2.58 & 5.0 & 5765 & 763 & 6452 & 3036 & 102 & 3161 & 1.90 \\
\hline $10-100$ & 10 & 100 & 2.52 & 7.5 & 4850 & 341 & 5147 & 2677 & 262 & 2889 & 1.81 \\
\hline $10-100 \mathrm{~N}$ & 10 & 100 & 2.52 & 7.5 & 5505 & 837 & 6239 & 3145 & 166 & 3243 & 1.75 \\
\hline $30-20$ & 30 & 20 & 2.33 & 15.0 & 4469 & 267 & 4656 & 2787 & 203 & 2924 & 1.60 \\
\hline $30-100$ & 30 & 100 & 2.37 & 13.5 & 4478 & 400 & 4648 & 2729 & 152 & 2853 & 1.64 \\
\hline $30-200$ & 30 & 200 & 2.41 & 12.2 & 4530 & 352 & 4770 & 2773 & 292 & & 1.63 \\
\hline $50-20-2$ & 50 & 20 & 2.27 & 18.0 & 4069 & 259 & 4345 & 2367 & 119 & 2464 & 1.72 \\
\hline $50-100-2$ & 50 & 100 & 2.30 & 16.7 & 4060 & 294 & 4317 & 2432 & 56 & 2412 & 1.67 \\
\hline $50-200-2$ & 50 & 200 & 2.32 & 16.0 & 4341 & 120 & 4339 & 2538 & 121 & 2624 & 1.71 \\
\hline $50-20-\mathrm{R}$ & 50 & 20 & 2.14 & 22.6 & 4022 & 295 & 4286 & 2500 & 123 & 2565 & 1.61 \\
\hline $50-20 \mathrm{~F}-\mathrm{R}$ & 50 & 20 & 2.14 & 22.6 & 4490 & 331 & 4811 & 2592 & 47 & 2648 & 1.73 \\
\hline $50-100-\mathrm{R}$ & 50 & 100 & 2.21 & 20.0 & 3988 & 147 & 4112 & 2465 & 128 & 2569 & 1.62 \\
\hline $50-200-\mathrm{R}$ & 50 & 200 & 2.24 & 19.0 & 4101 & 223 & 4225 & 2514 & 141 & 2618 & 1.63 \\
\hline $50-200 \mathrm{~F}-\mathrm{R}$ & 50 & 200 & 2.24 & 19.0 & 4988 & 305 & 5239 & 2879 & 32 & 2917 & 1.73 \\
\hline 70-20 & 70 & 20 & 2.10 & 24.5 & 3761 & 281 & 3943 & 2269 & 137 & 2333 & 1.66 \\
\hline $70-20 \mathrm{~N}$ & 70 & 20 & 2.10 & 24.5 & 4551 & 341 & 4866 & 2635 & 134 & 2713 & 1.73 \\
\hline $70-100$ & 70 & 100 & 2.19 & 21.5 & 3981 & 869 & 3982 & 2335 & 164 & 2434 & 1.70 \\
\hline $70-100 \mathrm{~N}$ & 70 & 100 & 2.19 & 21.5 & 4823 & 264 & 5183 & 2980 & 612 & 3009 & 1.62 \\
\hline $70-200$ & 70 & 200 & 2.24 & 19.7 & 3906 & 922 & 3975 & 2402 & 91 & 2473 & 1.63 \\
\hline 100-20 & 100 & 20 & 2.42 & 14.1 & 3773 & 235 & 3997 & 2516 & 149 & 2647 & 1.50 \\
\hline $100-100$ & 100 & 100 & 2.48 & 12.1 & 3753 & 200 & 3937 & 2490 & 151 & 2638 & 1.51 \\
\hline $100-200$ & 100 & 200 & 2.49 & 11.9 & 3920 & 373 & 3941 & 2416 & 118 & 2508 & 1.62 \\
\hline
\end{tabular}

${ }^{a} \mathrm{~V}_{\mathrm{P} 400}$ and $\mathrm{V}_{\mathrm{S} 400}$ are the velocities measured at $400 \mathrm{MPa} \mathrm{P}_{\mathrm{C}}$ (values at $400 \mathrm{MPa} \mathrm{P}_{\mathrm{C}}$ may represent the intrinsic crystal calcite-muscovite $\mathrm{V}_{\mathrm{P}}$ and $\mathrm{V}_{\mathrm{S}}$ more accurately since porosity or cracks contribute less to the seismic velocities at this confining pressure). $\rho-$ Density; $\varphi-$ Porosity. 

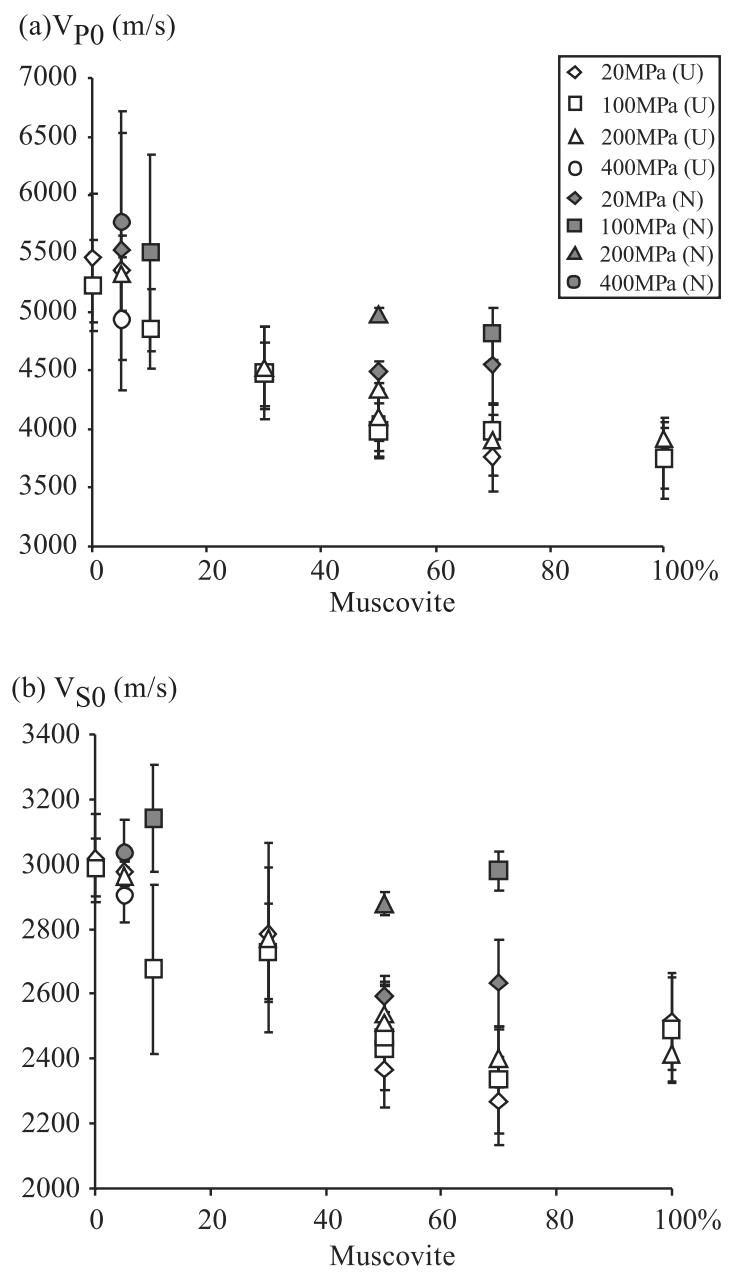

Figure 5. Experimentally determined (a) $\mathrm{V}_{\mathrm{P} 0}$ and (b) $\mathrm{V}_{\mathrm{S} 0}$. The error bars represent the size of the fiducial limits of the fitted regression at room pressure. The letter "U" refers to samples drilled with their long-axes parallel to the axis of compaction, whereas " $\mathrm{N}$ " refers to samples drilled normal to the axis of compaction.

actual value of muscovite $\left(\sim 2.82 \mathrm{~g} / \mathrm{cm}^{3}\right.$ [Schmidt et al., 2008]).

\subsection{Measured Seismic Velocities and Anisotropy}

[14] Seismic velocities, which were measured parallel and normal to the axis of compression, are listed in Table 1 with their respective errors and illustrated in Figure 5. Seismic velocities display an inverse relationship to the muscovite content, where increasing muscovite content leads to a decrease of P- and S-wave velocities. The degree of sample compression also influences $\mathrm{V}_{\mathrm{P} 0}$ and $\mathrm{V}_{\mathrm{S} 0}$, and greater compaction generally leads to increased velocity parallel to the foliation plane and decreased velocity normal to the foliation. $\mathrm{V}_{\mathrm{P} 0}$ is highest normal to the axis of compaction for specimen 5-40N (5\% muscovite, $40 \mathrm{MPa}$ load) and lowest parallel to the compaction axis for 70-20 (70\% muscovite, $20 \mathrm{MPa}$ load; Figure 5a). Velocities are consistently higher along the compression axis compared to parallel with the compression axis, giving rise to a seismic anisotropy. $\mathrm{V}_{\mathrm{SO}}$ displays a similar trend as $\mathrm{V}_{\mathrm{P} 0}$. Highest $\mathrm{V}_{\mathrm{S} 0}$ are recorded for a specimen that contains $10 \%$ muscovite, compressed with
$100 \mathrm{MPa}$ uniaxial load, drilled parallel to the foliation plane. The lowest shear wave velocities are attained in a specimen with $70 \%$ muscovite content, compressed with a $20 \mathrm{MPa}$ uniaxial load normal to the plane of foliation. The error bounds are greater for compressional waves compared to shear waves, indicating higher uncertainties for the determination of $\mathrm{P}$ wave velocities.

[15] The seismic anisotropy increases with increasing muscovite content. Anisotropy of P- and S-waves could be determined for seven synthetic samples (Figure 6a and Table 1). In general the anisotropy is high for samples with high muscovite content and high UCP loads. The measured S-wave anisotropy does not refer to the shear wave splitting, but rather to the percentage difference for S-wave measurements normal and parallel to the axis of compression. This definition is used because only one shear wave was measured in the plane normal to the compression axis, polarized in the plane perpendicular to the symmetry axis (therefore being the fast S-wave); the perpendicularly polarized shear wave was not measured in the foliation plane, but is expected to have similar velocity to a shear wave that propagates along compression axis since the material is transverse isotropic [see, e.g., Gautam and Wong, 2006; Hornby, 1998; Thomsen, 1986]. Specimen 10-100 (10\% muscovite content, pressed with $100 \mathrm{MPa}$ load) deviates from this trend, and

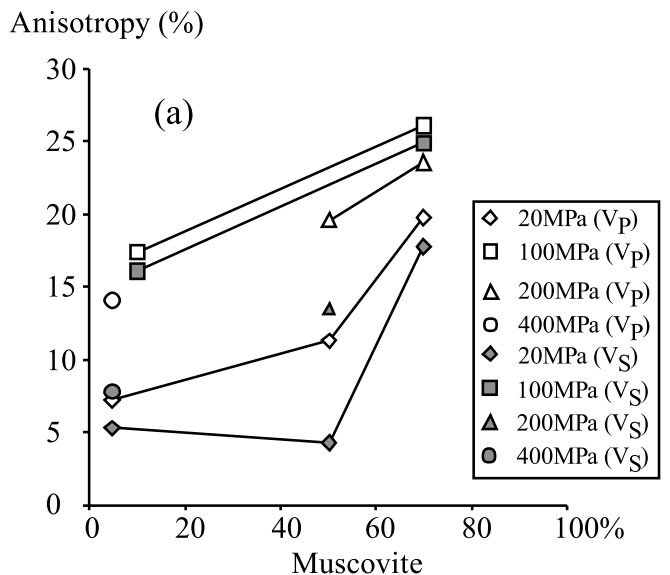

VP0 Anisotropy (\%)

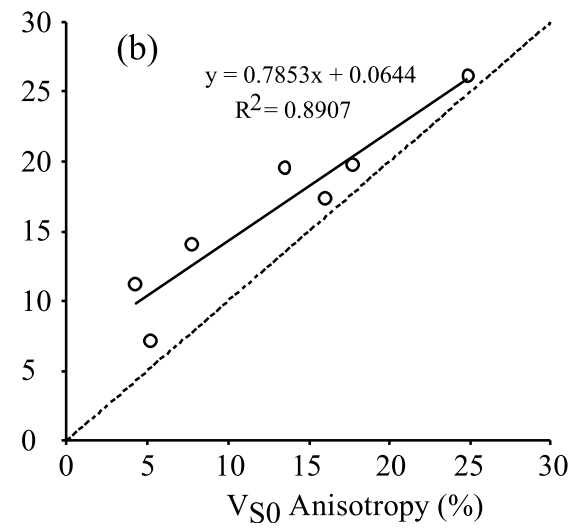

Figure 6. (a) Measured seismic anisotropy for $V_{P}$ and $V_{S}$, displayed for different applied uniaxial stresses. (b) Anisotropy of $\mathrm{V}_{\mathrm{P}}$ shown as a function of anisotropy of $\mathrm{V}_{\mathrm{S}}$. Dotted line represents the 1:1 line. 
Table 2. Calculated Seismic Velocities, Based on Sample $\mathrm{CPO}^{\mathrm{a}}$

\begin{tabular}{|c|c|c|c|c|c|c|c|c|c|c|}
\hline Sample & $\mathrm{P}$ & $\mathrm{Mu}(\%)$ & VP (U) & $\mathrm{VP}(\mathrm{N})$ & Vpanis (\%) & VS1 $(U)^{b}$ & $\operatorname{VS} 1(\mathrm{~N})^{\mathrm{b}}$ & $\mathrm{VS} 2(\mathrm{U})^{\mathrm{b}}$ & $\operatorname{VS} 2(N)^{b}$ & Maximum dVS $(\mathrm{m} / \mathrm{s})$ \\
\hline $0-20$ & 20 & 0 & 6600 & 6700 & 1.5 & 3440 & 3470 & 3430 & 3440 & 30 \\
\hline $0-100$ & 100 & 0 & 6400 & 6830 & 6.5 & 3390 & 3540 & 3380 & 3420 & 160 \\
\hline $0-400$ & 400 & 0 & 6340 & 6870 & 8.0 & 3370 & 3570 & 3360 & 3410 & 210 \\
\hline $5-40$ & 40 & 5 & 6420 & 6780 & 5.5 & 3400 & 3540 & 3390 & 3420 & 150 \\
\hline $5-100$ & 100 & 5 & 6490 & 6720 & 3.5 & 3420 & 3510 & 3420 & 3430 & 90 \\
\hline $5-200-2$ & 200 & 5 & 6220 & 6930 & 10.8 & 3350 & 3640 & 3340 & 3410 & 300 \\
\hline $5-200-3$ & 200 & 5 & 6360 & 6840 & 7.3 & 3380 & 3570 & 3370 & 3430 & 200 \\
\hline $5-400-2$ & 400 & 5 & 6220 & 6910 & 10.5 & 3340 & 3630 & 3330 & 3400 & 300 \\
\hline $5-400-3$ & 400 & 5 & 6300 & 6870 & 8.7 & 3350 & 3610 & 3340 & 3430 & 270 \\
\hline $10-20$ & 20 & 10 & 6500 & 6680 & 2.7 & 3430 & 3500 & 3420 & 3430 & 70 \\
\hline $10-100$ & 100 & 10 & 6340 & 6790 & 6.9 & 3380 & 3570 & 3370 & 3440 & 200 \\
\hline $10-200$ & 200 & 10 & 6330 & 6780 & 6.9 & 3390 & 3570 & 3380 & 3410 & 180 \\
\hline $30-20$ & 20 & 30 & 6230 & 6700 & 7.3 & 3360 & 3610 & 3350 & 3440 & 260 \\
\hline $30-100$ & 100 & 30 & 6010 & 6910 & 13.9 & 3260 & 3770 & 3260 & 3450 & 520 \\
\hline $30-200$ & 200 & 30 & 5760 & 7450 & 25.6 & 3100 & 4170 & 3100 & 3590 & 1070 \\
\hline $50-20-2$ & 20 & 50 & 5740 & 6950 & 19.1 & 3210 & 3910 & 3200 & 3430 & 710 \\
\hline $50-20-\mathrm{s}$ & 20 & 50 & 5860 & 6820 & 15.1 & 3260 & 3810 & 3260 & 3430 & 550 \\
\hline $50-100-2$ & 100 & 50 & 5750 & 6940 & 18.8 & 3190 & 3890 & 3180 & 3450 & 710 \\
\hline $50-100-\mathrm{s}$ & 100 & 50 & 5710 & 6970 & 19.9 & 3180 & 3910 & 3170 & 3440 & 740 \\
\hline $50-200-2$ & 200 & 50 & 5570 & 7170 & 25.1 & 3090 & 4070 & 3080 & 3460 & 990 \\
\hline $70-100-r$ & 100 & 70 & 5220 & 7340 & 33.8 & 2960 & 4290 & 2950 & 3460 & 1340 \\
\hline $70-100-\mathrm{s}$ & 100 & 70 & 5240 & 7260 & 32.3 & 3000 & 4240 & 2990 & 3420 & 1250 \\
\hline $70-200$ & 200 & 70 & 5230 & 7300 & 33.0 & 2960 & 4260 & 2960 & 3450 & 1300 \\
\hline $100-20$ & 20 & 100 & 5110 & 6940 & 30.0 & 3070 & 4120 & 3060 & 3380 & 1060 \\
\hline $100-100$ & 100 & 100 & 4950 & 7180 & 37.0 & 2920 & 4310 & 2910 & 3410 & 1400 \\
\hline $100-200$ & 200 & 100 & 4950 & 7240 & 38.0 & 2870 & 4340 & 2870 & 3430 & 1470 \\
\hline
\end{tabular}

"The letter " $U$ " refers to samples drilled with their long-axes parallel to the axis of compaction, whereas "N" refer to samples drilled normal to the axis of compaction.

${ }^{\mathrm{b}}$ Units in $\mathrm{m} / \mathrm{s}$.

displays a greater anisotropy for both $V_{P 0}$ and $V_{S 0}$ than expected from the overall trend of other specimens. $V_{P}$ and $\mathrm{V}_{\mathrm{S}}$ anisotropies are positively correlated among the specimens that were investigated (Figure 6b), although the best fit line $\left(\mathrm{R}^{2}=0.89\right)$ for the two data sets do not intersect at the origin, since the anisotropy of $V_{P}$ is higher than the anisotropy of $\mathrm{V}_{\mathrm{S}}$. Shear wave splitting is not observed along the compression axis (axis of symmetry), as is expected in a transverse isotropic material.

\section{Calculated Seismic Velocities and Elastic Constants}

[16] Calculated $\mathrm{V}_{\mathrm{P}}$ and $\mathrm{V}_{\mathrm{S}}$ are listed in Table 2, parallel and perpendicular to the axis of compression, and are shown using cross-sections of equal angle projections on which the seismic velocities are plotted (divided into $5^{\circ} \times 5^{\circ}$ areas), as presented in Figures 7 and 8. Each cross-section represents a velocity profile from parallel to perpendicular to the axis of compression. The sections display $\mathrm{V}_{\mathrm{P}}$ and $\mathrm{V}_{\mathrm{S}}$ velocities that are higher normal $\left(90^{\circ}\right)$ compared to parallel $\left(0^{\circ}\right)$ to the compression axis. The difference becomes more pronounced with increased UCP load and mica content.

[17] Normal to foliation $V_{P}$ varies between $6600 \mathrm{~m} / \mathrm{s}$ to $4950 \mathrm{~m} / \mathrm{s}$ and is largest for the $100 \%$ calcite sample compacted with $20 \mathrm{MPa}$ uniaxial load; the lowest $\mathrm{V}_{\mathrm{P}}$ normal to foliation is found for the two $100 \%$ muscovite samples compacted with 100 and $200 \mathrm{MPa}$ uniaxial load. The fast $\left(\mathrm{V}_{\mathrm{S} 1}\right)$ and slow $\left(\mathrm{V}_{\mathrm{S} 2}\right) \mathrm{S}$-waves have similar velocities when propagating normal to the foliation plane without noticeable
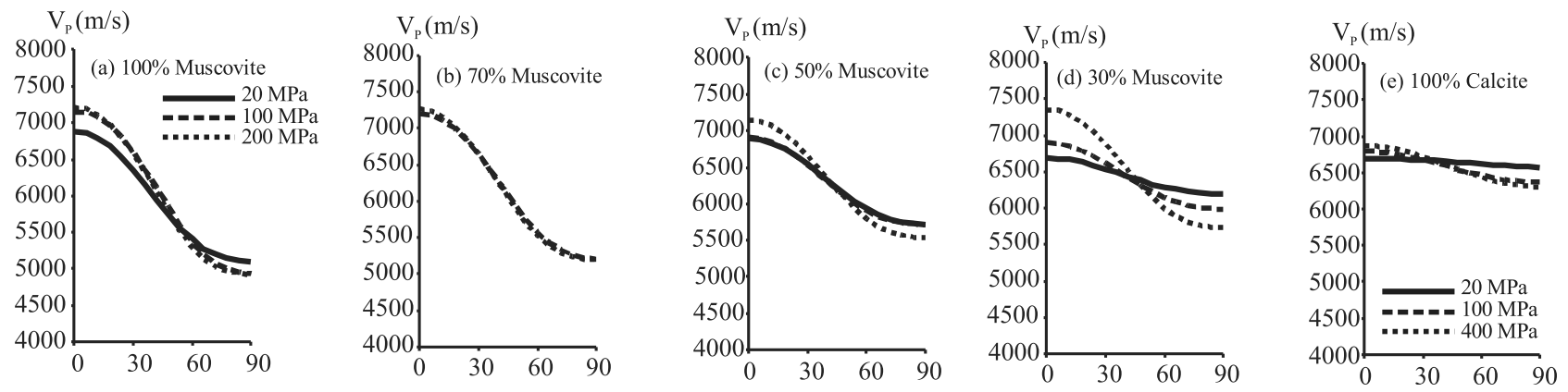

Figure 7. A series of cross-sections cutting through equal area nets, for the range of muscovite compositions, which display variation of $\mathrm{V}_{\mathrm{P}}$ velocities with respect to the angle of incidence to the foliation plane. The foliation plane is indicated by the $0^{\circ}$ angle on each side of the equal area net, where the angle of $90^{\circ}$ refer to the vertical axis in the center of the stereonet. 

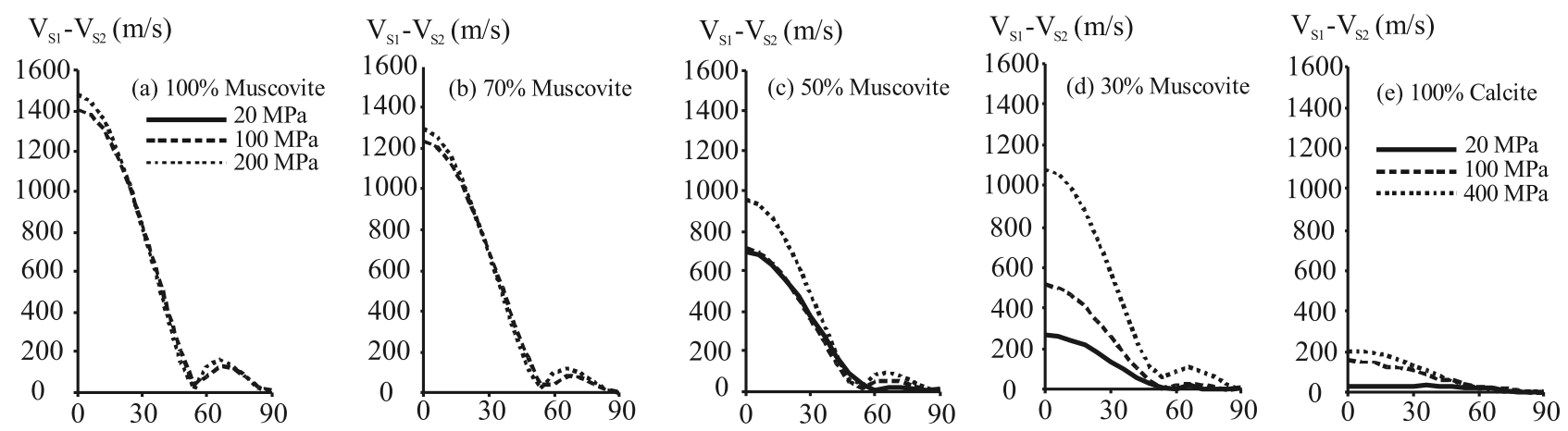

Figure 8. Cross-sections as described in Figure 7 that show the shear wave splitting $\left(V_{S 1}-V_{S 2}\right)$ as a function of angle of incidence to the foliation plane. The foliation plane is indicated by the $0^{\circ}$ angle on each side of the stereonet, where the angle of $90^{\circ}$ refer to the vertical axis in the center of the equal area net.

shear wave splitting $\left(\mathrm{dV}_{\mathrm{S}}\right)$. Splitting becomes prominent when $\mathrm{S}$-waves propagate in the foliation plane, which is typical for a transverse isotropic symmetry [e.g., Wong et al., 2008], and the intensity of $\mathrm{dV}_{\mathrm{S}}$ increases with higher muscovite content (Figure 8). Minor splitting is also observed at about $60-70^{\circ}$ angles to the foliation plane. Shear wave velocities normal to foliation vary between $3440 \mathrm{~m} / \mathrm{s}$ for $100 \%$ calcite compacted with $20 \mathrm{MPa}$ uniaxial stress and $2870 \mathrm{~m} / \mathrm{s}$ for $100 \%$ muscovite compacted with $200 \mathrm{MPa}$.

[18] In contrast to waves propagating along the compression axis, seismic velocities within the plane normal to the compression axis are higher and increase with greater muscovite content (Table 2). The highest $\mathrm{V}_{\mathrm{P}}$ and $\mathrm{V}_{\mathrm{S} 1}$ are found for $70 \%$ muscovite content. Note that the slow $\mathrm{S}$-wave $\left(\mathrm{V}_{\mathrm{S} 2}\right)$ has similar velocities regardless of whether it is propagating parallel or normal to the compression axis, whereas the fast $\mathrm{S}$-wave, $\mathrm{V}_{\mathrm{S} 1}$, varies with respect to its propagation orientation.

[19] The modeled seismic velocities display a wide range of anisotropy (Figure 9a and Table 2), from nearly isotropic in pure calcite pressed with $20 \mathrm{MPa}$ uniaxial load $\left(\mathrm{AV}_{\mathrm{P}}=\right.$ $1.5 \% ; \mathrm{dV}_{\mathrm{S}}=30 \mathrm{~m} / \mathrm{s}$ ) to highly anisotropic for pure muscovite pressed with $200 \mathrm{MPa}$ uniaxial load $\left(\mathrm{AV}_{\mathrm{P}}=38 \%\right.$; $\left.\mathrm{dV}_{\mathrm{S}}=1470 \mathrm{~m} / \mathrm{s}\right)$. Samples pressed with $20 \mathrm{MPa}$ are about $5 \%$ less anisotropic than samples that experienced larger loads (Figure 9b). However, at higher loads the anisotropies are similar for samples with muscovite contents less than $50 \%$, but differences between samples become apparent when the muscovite content increases above $50 \%$.

\section{Discussion}

\subsection{Elastic Properties of the Calcite-Muscovite}

[20] Figure 10a compares the seismic velocities that were measured on the calcite-muscovite aggregates with the velocities computed from the texture data. Calculated velocities are consistently higher than measured data, indicating that the calculated values, which are based on the ODF, volume fraction of each mineral and their singlecrystal elastic constants, overestimate the actual $V_{P}$ and $V_{S}$; the difference is noticeably larger for $V_{P}$ than for $V_{S}$. Calculated velocities do not consider the presence of pores, or any effect arising from microstructures in the aggregates (e.g., a matrix framework effect). $V_{P}$ anisotropy also shows a difference between the measured and modeled values
(Figure 10b), where for low muscovite content the disagreement is smaller than for high content. At 50 and $70 \%$ muscovite content the modeled $\mathrm{V}_{\mathrm{P}}$ anisotropy values are clearly higher than the measured ones.

[21] The differences between experimentally determined velocities and calculated velocities are likely a consequence of the following effects:

[22] 1) The matrix framework, for which grain contacts are limited (granular-type) rather than inter-locking (crystalline-type), which affect the strength and seismic
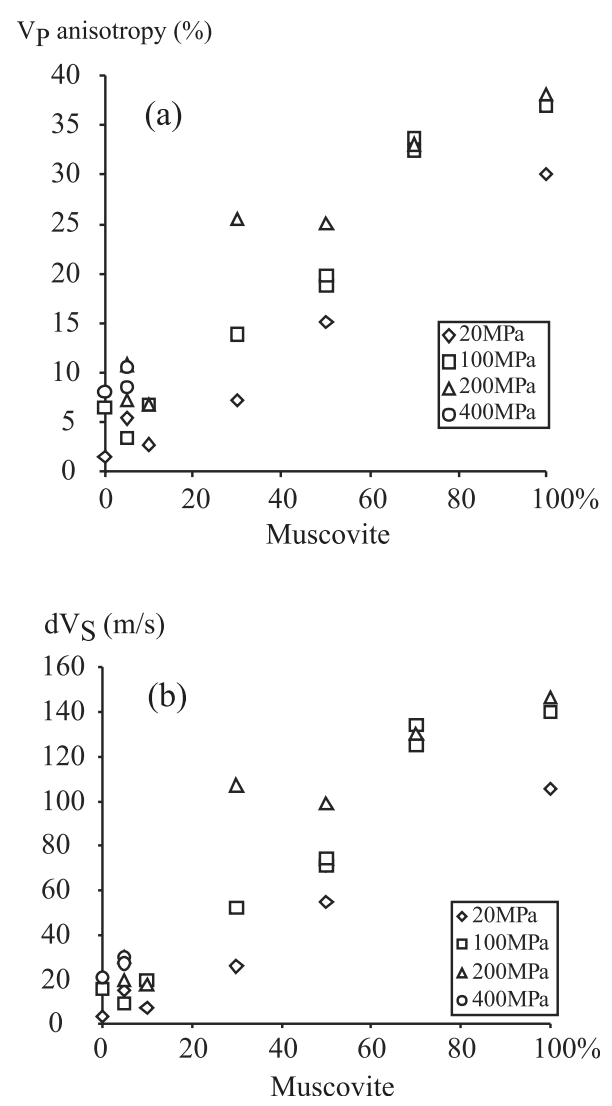

Figure 9. The texture derived anisotropy for (a) $V_{P}$ and (b) shear wave splitting $\left(d_{V_{S}}=V_{S 1}-V_{S 2}\right)$ with respect to calcite-muscovite content. Samples compressed with various UCP loads are indicated in the legend. 
Calculated V $(\mathrm{m} / \mathrm{s})$
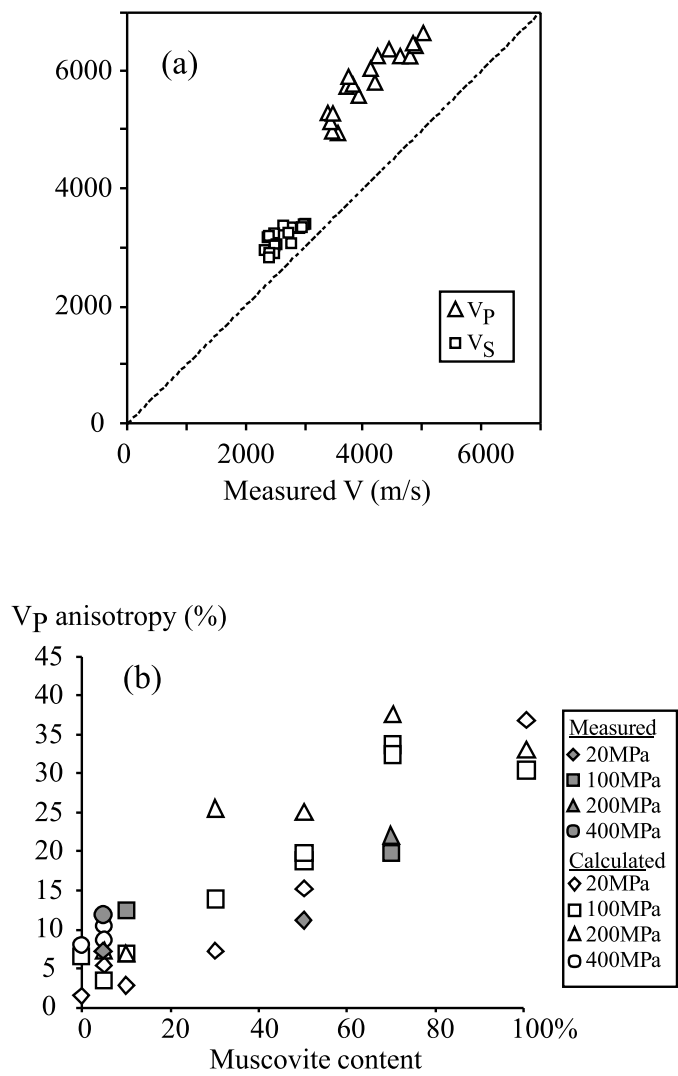

Figure 10. (a) Measured $\left(\mathrm{V}_{\mathrm{P} 0}\right.$ and $\left.\mathrm{V}_{\mathrm{S} 0}\right)$ and texture derived seismic velocities; (b) measured and texture derived $V_{P}$ anisotropies $\left(\mathrm{AV}_{\mathrm{P}}\right)$ as a function of muscovite content for various UCP loads.

velocities significantly [Bernabé et al., 1992; Anselmetti and Eberli, 1993; Verwer et al., 2008].

[23] 2) Porous spaces and cracks were not completely closed even at high confining pressures $(>300 \mathrm{MPa})$, which reduce the measured velocities. For example, highly oriented thin cracks, parallel to the foliation, would reinforce the transverse isotropic mineral texture. Alternatively, spherical pores would have the opposite effect, since waves propagating parallel and normal to the compression axis would be equally affected by the porosity and may decrease the overall seismic anisotropy. The latter suggestion has been shown in calculated velocities for anisotropic rocks where the inclusions are spherical [Mainprice, 1997].

[24] 3) Systematic inaccuracy in picking the arrival times of acoustic waves of the measured velocities and calibration errors, could lead to an error. Such errors usually do not amount to more than a $\sim 1-2 \%$ error when the pulse transmission technique is used [Birch, 1960; Burlini and Fountain, 1993].

[25] Since any systematic inaccuracies in the experimental procedure would account for $1-2 \%$ of the discrepancies in velocities that are observed for our measurements (Figures $8 \mathrm{a}$ and $8 \mathrm{~b}$ ), we consider explanations 1) and 2) as the main causes for the observed differences. In addition, it should be noted that since we use confining pressures up to $475 \mathrm{MPa}$ the elastic constants of calcite and muscovite will change as a function of pressure. Dandekar [1968] listed the elastic constants for single-crystal calcite with respect to changing pressures, up to $600 \mathrm{MPa}$. In general the pressure effect was small ( $\sim 1.5 \%$ or less), except for the stiffness constant $\mathrm{C}_{13}$, which increased about $11 \%$ from room pressure to $600 \mathrm{MPa}$. Since we measure seismic velocities for cores drilled parallel and normal to the axis of symmetry in a transverse isotropic material, $C_{13}$ is not likely to greatly influence the $V_{P}$ and $V_{S}$ in this sample arrangement. The effect of pressure on the elastic constants of muscovite is less well known, and no documented experimental data is currently available to the authors' knowledge. We do not consider the change in elastic constants as a function of pressure to alter our interpretations over the experimental pressure range $(\leq 475 \mathrm{MPa})$.

[26] The matrix framework, in the sense of its petrographic classification, has been shown to depress seismic velocities in rocks due to the effect of grain boundary contacts [Verwer et al., 2008; Voltolini et al., 2009]. An inter-crystalline framework with low porosity more effectively transmits the acoustic energy over grain boundaries and may more closely resemble the modeled seismic velocities. In other words, the material is stiffer in a crystalline solid, compared to a granular solid, not exclusively due to the differences in porosity of the two solids but in part due to the framework of the solid. Anselmetti et al. [1997] found that seismic velocities in carbonates could differ as much as $2500 \mathrm{~m} / \mathrm{s}$ from the expected seismic velocities, which they attributed to the amount of porosity in the carbonates and their diagenetic condition. In their study on mechanical compaction of carbonate muds, which had an initial porosity of about $60 \%$, the porosity could not be reduced below $25 \%$ at $170 \mathrm{MPa}$ uniaxial pressure due to the packing of carbonate grains at high pressure. Verwer et al. [2008] similarly observed that carbonates with high porosity, supported by a granular framework were distinctly different with respect to seismic velocities and Poisson's ratio to low porosity crystalline carbonates. Granular framework rocks have also been studied with respect to cementation of the matrix, and its effect on the strength and elastic properties. In a granular framework it appears that the amount of cement in the rock is less important than where the cement is located.

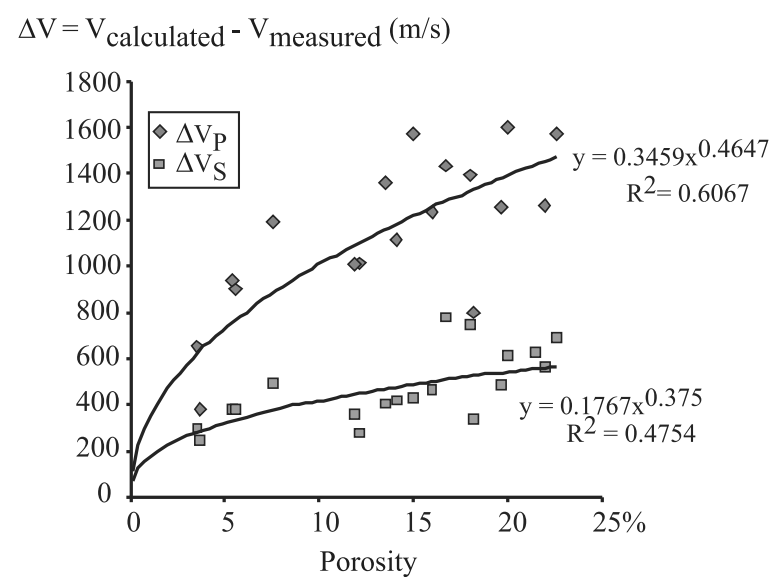

Figure 11. Difference between modeled and measured velocities $(\Delta V)$ as a function of porosity for $V_{P}$ and $V_{S}$; the two data sets are fitted with a power law function. 


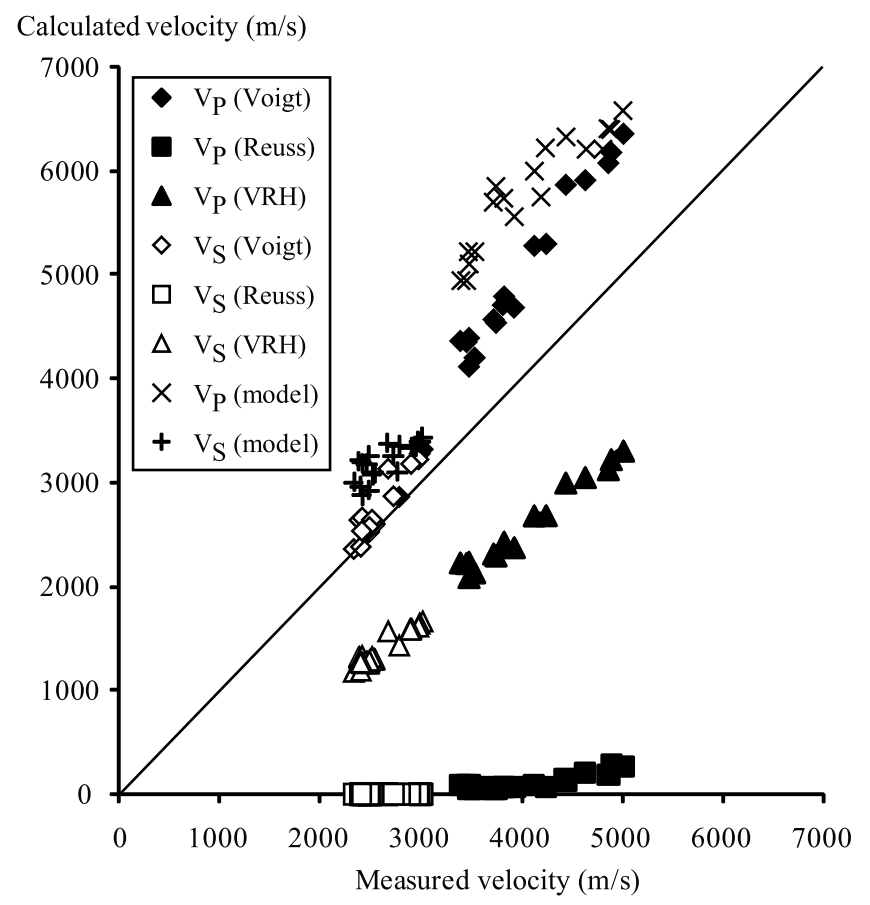

Figure 12. Seismic velocities predicted with the Voigt, Reuss, and VRH averages, for P- and S-waves. The line represents the 1:1 correlation between measured and calculated seismic velocities.

Bernabé et al. [1992] observed that cement filling between the grain-boundaries stabilized the movement of grains and strengthened the rock more than the actual amount of cement. A cemented granular material, where grains are locked together, is effectively stiffer than for a material, in which the cement does not coat the grain boundaries [Dvorkin et al., 1991, 1994; Bernabé et al., 1992; Den Brok et al., 1997]. For the samples used in this study, Schmidt et al. [2008] showed that only the pure calcite sample compressed with $400 \mathrm{MPa}$ show evidence for a recrystallized microtexture, whereas samples that include muscovite do not display evidence for recrystallization subsequent to hot isostatic pressing. Most samples are therefore inferred to have a granular framework. Although we cannot quantify this effect, it probably contributes to the decrease in velocities, which are observed in the measured versus the modeled data.

[27] With regards to the amount of pore space, we observe that initial porosities are high, especially when the muscovite content is high. The amount, geometry and spatial distribution of pores and cracks will influence the $V_{P}$ and $V_{S}$ propagation, even at confining pressures up to $400 \mathrm{MPa}$. The velocity differences $\left(\Delta \mathrm{V}=\mathrm{V}_{\text {modeled }}-\mathrm{V}_{\text {measured }}\right)$ as a function of porosity display a nonlinear relationship for both $\Delta \mathrm{V}_{\mathrm{p}}$ and $\Delta \mathrm{V}_{\mathrm{s}}$ (Figure 11). An empirical power law fit suggests that measured seismic velocities are greatly affected even by a small number of pores or cracks. It can be seen that the $\mathrm{P}$ waves are more affected by the presence of pores than are S-waves. As mentioned above, the preferred orientation of pores and their shapes are known to affect travel-times of acoustic waves [e.g., Berryman, 1995; Birch, 1960; Nur and Simmons, 1969]. Specific pore shapes (i.e., aspect ratio) also influences the effective $\mathrm{P}_{\mathrm{C}}$ needed to close the pores or cavities in a dry rock [Jones and Meredith, 1998]. Pore space anisotropy in the synthetic samples is inferred from the fact that we use uniaxial compaction during sample preparation. The measured $V_{P}$ and $V_{S}$ are affected differently with regards to the amount of porosity, where $V_{P}$ shows a comparably larger decrease than $\mathrm{V}_{\mathrm{S}}$. This behavior was observed by Nur and Simmons [1969] in experiments on low-porosity granites. Anderson et al. [1974] have shown models where $V_{S}$ is less affected by the presence of cracks compared to $\mathrm{V}_{\mathrm{P}}$. More recently Nishizawa and Yoshino [2001] and Sarout and Guéguen [2008a, 2008b] have shown for modeled phase velocities in mica-rich rocks that cracks affect the $\mathrm{P}$ wave velocities more than they affect $\mathrm{S}$-wave velocities. Nishizawa and Yoshino [2001] observed a notable increase in P wave anisotropy as thin or penny-shaped cracks were added to the rock, whereas the S-wave anisotropy, i.e., the polarization of the $\mathrm{S}$-waves is less affected. This effect, with S-waves being less affected by the increase in porosity, is also observed in our results for measured $\mathrm{P}$ - and S-waves (Figures 5 and 11), thus confirming the modeled results.

[28] A recent study by Voltolini et al. [2009] showed that calculated velocities always overestimate the measured velocities for a set of synthetic kaolinite-illite-quartz aggregates. The authors measured seismic velocities only along the axis of compression and found that the measured velocities were commonly only half the modeled values. They attributed the difference due to properties of the matrix and porosity. Interestingly, their calculated $\mathrm{V}_{\mathrm{P}}$ anisotropy ranged from $0 \%$, for pure quartz silt samples, up to $44 \%$ for pure clay samples compressed with a $50 \mathrm{MPa}$ uniaxial load. This value is comparable to the average calculated anisotropy of $34 \%$ that we obtain for our synthetic samples containing 70 and $100 \%$ muscovite. Shear wave splitting also varied, being greatest at $1230 \mathrm{~m} / \mathrm{s}$, for the pure clay samples in the study of Voltolini et al. [2009], which compares well with our average value of $1.30 \mathrm{~km} / \mathrm{s}$ for 70 and $100 \%$ muscovite content. The calculated velocities of the nearly isotropic quartz samples shown by Voltolini et al. [2009] also agree with the calculated low (a few percent) anisotropy of pure calcite samples presented as part of this study. Although calcite tends to have a preferred crystal orientation, its contribution to seismic anisotropy seems to be small in natural settings compared to minerals that display both grain shape anisotropy and high intrinsic anisotropy. (e.g., sheet silicates and clay minerals), as shown for example by Wenk et al. [2008]. Voltolini et al. [2009] attributed differences between measured and calculated seismic velocities in their synthetic quartz-illite-kaolinite samples to the amount of porosity and limited grain contacts, similar to this study.

\subsection{Seismic Velocities in Porous Media}

[29] In order to better constrain the effect of pores on the measured velocities of acoustic waves of the synthetic aggregates we consider modeling the porosity using effective medium theory. For this purpose two modeling schemes are used. The first model simply uses Voigt, Reuss, and VoigtReuss-Hill (VRH) averaging schemes. It is possible to use these schemes to predict seismic velocities based on the elastic tensor, which was previously calculated based on the modal composition of calcite and muscovite and their 

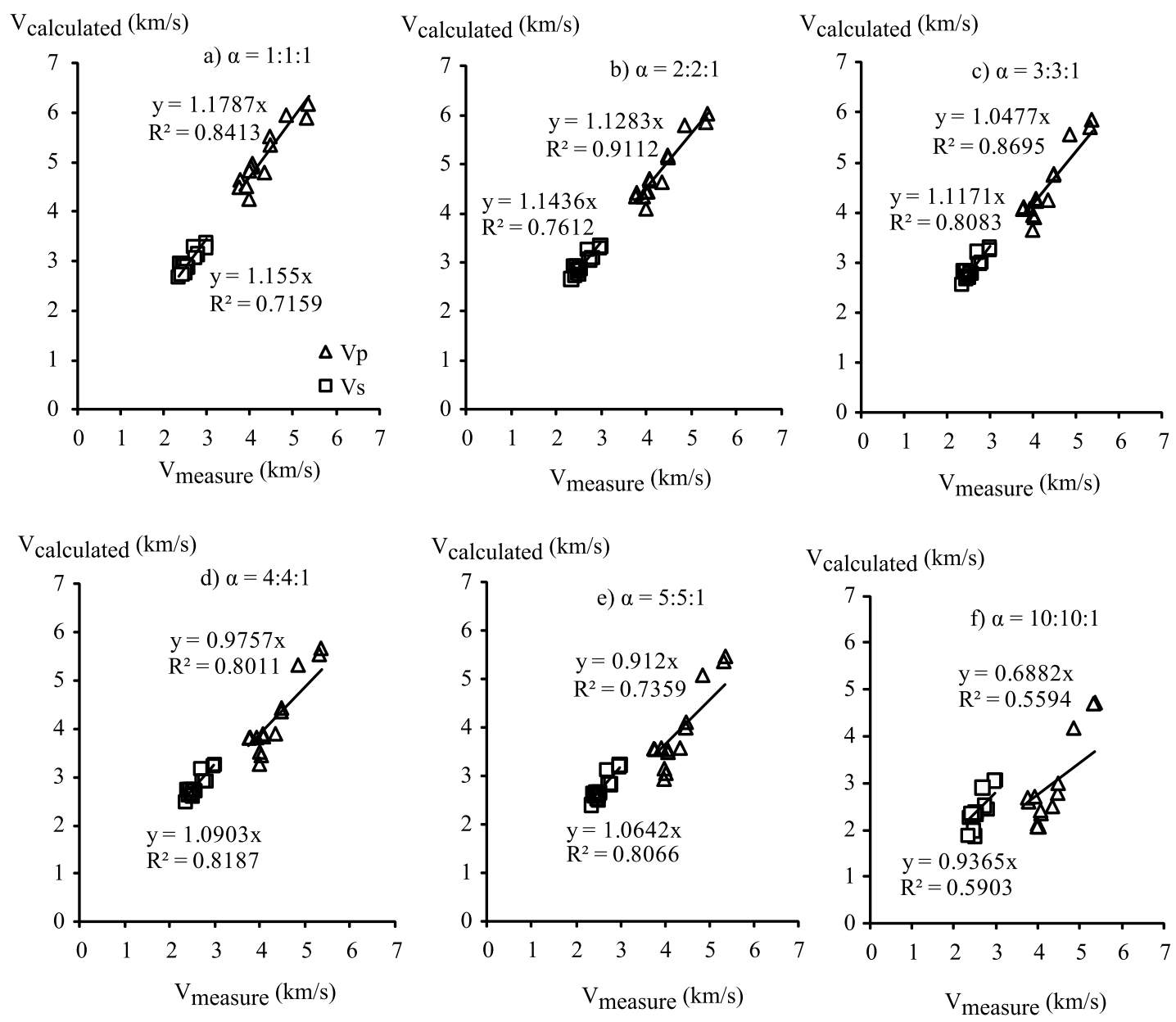

Figure 13. Seismic velocities predicted with the differential effective medium (DEM) model, considering several different pore aspect ratios $(\alpha)$, for $\mathrm{P}-$ and $\mathrm{S}$-waves.

texture (see Table S1), and the amount of air-filled pores. ${ }^{1}$ The computation of the elastic properties for the solid were described in section 2.3 and results for the VRH average of the solid calcite-muscovite mixtures were presented in section 4 . The pores are considered to be filled with air, and are given a bulk modulus of $1.42 \times 10^{5} \mathrm{~Pa}\left(1.42 \times 10^{-4} \mathrm{GPa}\right)$ and a shear modulus of 0 ; the density of air for the calculations is $1.2 \mathrm{~kg} / \mathrm{m}^{3}$. The results obtained from these averaging schemes predict a large envelope of possible seismic velocities (Figure 12), since the elastic moduli of the solid and air-filled pores are very different. In addition the VRH estimates suffer from the drawback that no particular geometric inference can be made, either for the solid or the shape of the pores.

[30] Because the elastic moduli of the two media are so different, we use a model that considers the geometric details of the solid (e.g., CPO), as well the shape of the pores in the solid. The pore- or crack-shape have a large influence on the elastic properties and seismic velocities in composite media as demonstrated in studies on the effect of inclusions, which has dominated the research of effective medium theory [e.g., Eshelby, 1957; Anderson et al., 1974]. Here we

\footnotetext{
${ }^{1}$ Auxiliary materials are available in the HTML. doi:10.1029/ 2009JB006523.
}

adopt the differential effective medium (DEM) model, which takes into account a heterogeneous background media, with triclinic symmetry, and inclusions with idealized ellipsoidal shape (the method is described in detail by Mainprice [1997]). A drawback of the DEM is that the inclusions are never considered to be connected, even at high concentrations, as is most likely the case for the porous framework. However, a connected pore framework is probably not different from the scenario of isolated pores in the current study, since the acoustic velocities were measured on samples in dry conditions and high frequency. The individual porosity for each sample in the calcite-muscovite series is considered to be ellipsoidal inclusions, presented in Figure 13. Inclusions are aligned in the medium such that their long-axes are normal to the axis of compression, and vary from spherical $(\mathrm{X}: \mathrm{Y}: \mathrm{Z}=1: 1: 1)$ to oblate rotational ellipsoids $(X: Y: Z=10: 10: 1)$. Only waves propagating parallel to the axis of compression are considered in Figure 13. Clearly, the more flattened the pores become, the larger is the decrease in the seismic velocity. Linear fits to the data sets, which are anchored to the intercept at zero in Figure 13, suggest that aspect ratios of pores between 3:3:1 and 4:4:1 are the most likely aspect ratios for the sample group as a whole, since the slope of the line between measured and predicted velocities is close to one. The resulting aspect ratio 


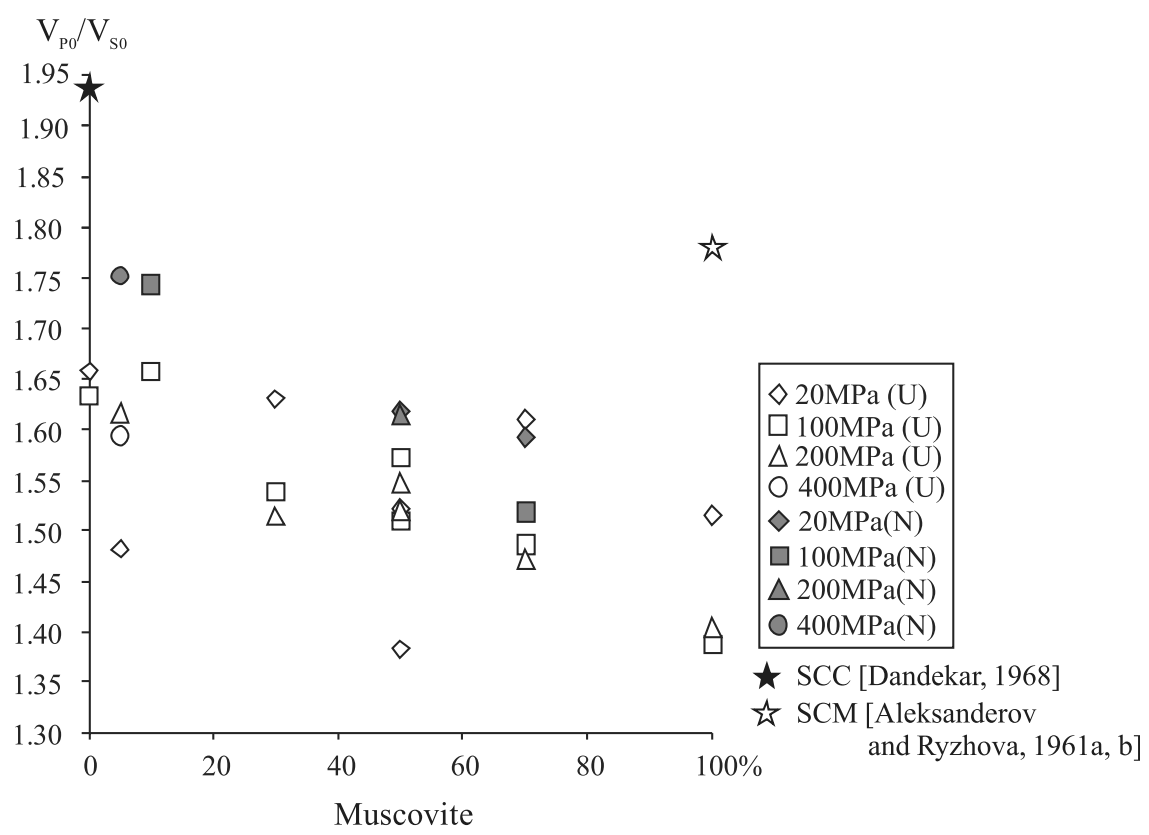

Figure 14. The ratio of measured $\mathrm{V}_{\mathrm{P}} / \mathrm{V}_{\mathrm{S}}$, parallel and perpendicular to the foliation plane, is displayed against the sample muscovite content. Single crystal $\mathrm{V}_{\mathrm{P}} / \mathrm{V}_{\mathrm{S}}$ for calcite and muscovite are indicated by stars. The letter " $U$ " refers to samples drilled with their long-axes parallel to the axis of compaction, whereas " $\mathrm{N}$ " refers to samples drilled normal to the axis of compaction.

(i.e., closer to spherical pores rather than thin cracks) can be understood by considering the interaction of euhedral or tabular calcite crystals with the thin platelets of mica. Bayuk et al. [2007], who studied the effective medium of natural shale, concluded that aspect ratios of pores were about 10:10:1 for their samples, due to the interaction of rounded grains of silt with platy clay particles. The stacking of plates together with spheres (or alternatively thin rectangular blocks or cubes) have also been considered in other works involving mica- and clay-rich rocks [Crawford et al., 2008; Hornby et al., 1994; Marion et al., 1992; Wenk et al., 2008], and the shape of the constituent grains is an important aspect of the physical properties of the matrix. However, it should be noted the aspect ratio of the pores likely changes as the composition of the aggregates changes. Here we have simply attempted to address the contribution of pores to the seismic velocities for the sample group.

\subsection{Implications for Crustal Rocks}

[31] Rocks containing clay minerals and mica, for example shale and carbonates, are of key importance in oil and gas field reservoir exploration, engineering geology and sequestration of $\mathrm{CO}_{2}$ and radioactive waste products. As a consequence the role of mica and clay minerals in rocks have received considerable attention [e.g., Bayuk et al., 2007; Cholach and Schmitt, 2006; Crawford et al., 2008; Hornby, 1998; Marion et al., 1992; Ulm and Abousleiman, 2006; Wenk et al., 2008]. These studies all have the common goal to understand the contribution of mica and clay minerals to the overall rock elastic and mechanical properties, ranging from the macroscopic to the microscopic scale. Muscovite is a sheet-silicate, but the similar structural properties of illite and muscovite have previously warranted the use of muscovite as an analog for illite, especially since the elastic constants of illite are not known [e.g., Wenk et al., 2008]. In the synthetic aggregates, muscovite has been shown to preferentially orient its basal plane normal to the axis of compression resulting from the platy shape of the grains. However, kinking is evident [Schmidt et al., 2008], indicating that muscovite undergoes brittle deformation during cold-pressing, and is not markedly affected by annealing when consolidated during hot isostatic pressing $\left(\sim 700^{\circ} \mathrm{C} ; 150 \mathrm{MPa}\right)$. Twinning is the dominant deformation mechanism for calcite, and from observations of thin sections it appears that glide on the twin-planes has occurred during UCP of samples [Schmidt et al., 2008]. From pole figures and the anisotropy of magnetic susceptibility, Schmidt et al. [2009] deduced a transverse isotropic texture. The method used to manufacture the synthetic aggregates display some processes analogous to nature, although importantly without a fluid component. For example, transverse isotropic textures are commonly observed in sedimentary rocks resulting from deposition and compaction of sediments [e.g., Johnston and Christensen, 1995], such as in calcareous deep-sea sediments, for which the seismic anisotropy was studied by Carlson et al. [1984] and Carlson and Christensen [1979]. These authors attributed seismic anisotropy recorded in deep-sea cores to burial depth, the layering effect of bedding, and a strong negative correlation between anisotropy and carbonate content. They observed that the anisotropy increased with greater sediment overburden and higher density of the sediment, as opposed to the influence of porosity, which lessened the seismic anisotropy.

[32] Valcke et al. [2006] used EBSD and X-ray diffraction goniometry methods to determine the texture and calculate the elastic properties and seismic anisotropy for various common sedimentary lithologies. They found that the main 
factor controlling the calculated anisotropy is the mineralogical composition of the rock. Phyllosilicate-rich rocks have larger anisotropies than quartz- and calcite-rich rocks, in large part due to the intrinsic physical properties of the sheet silicates. This feature is also observed in the calculated seismic anisotropies for our synthetic calcite-muscovite aggregates. In addition, Valcke et al. [2006] noticed that the constituent mineralogy of the sample influences the symmetry of the elastic anisotropy. Uniaxial compaction of phyllosilicates produces a strong transverse isotropic symmetry, as is described by the $\mathrm{CPO}, \mathrm{V}_{\mathrm{P}}$ anisotropy and $\mathrm{V}_{\mathrm{S}}$ splitting. To a lesser extent the transverse isotropic symmetry is also demonstrated by the $A V_{P}$ in calcite and its symmetry. Although the mode of deformation is different in the synthetic aggregates, mica-induced seismic anisotropy is important particularly in highly deformed areas such as shear or fault zones with strong preferred orientation of grains, which can attribute considerable to shear wave splitting and $\mathrm{P}$ wave anisotropy, [e.g., Burlini and Fountain, 1993; Jones and Nur, 1984; Nishizawa and Yoshino, 2001; Siegesmund and Kern, 1990].

[33] Finally we remark on the $\mathrm{V}_{\mathrm{P}} / \mathrm{V}_{\mathrm{S}}$ ratio (Figure 14), which is commonly used to discriminate lithologies. The variation in ratios for different lithologies is due largely to the differences in Poisson's ratio for the responsible matrix minerals, which consist dominantly of calcite and quartz (i.e., carbonate versus sandstone [Guégen and Palciauskas, 1994]). Figure 14 shows $\mathrm{V}_{\mathrm{P} 0} / \mathrm{V}_{\mathrm{S} 0}$ ratios for the synthetic aggregates and these vary considerably for different calcite to muscovite ratios, as well as for the load used during UCP. Samples compacted with low pressures, i.e., 20MPa, show great scatter with respect to the muscovite content. Limestone commonly displays $\mathrm{V}_{\mathrm{P}} / \mathrm{V}_{\mathrm{S}} \sim 1.7-2.0$, with $\mathrm{P}$ wave velocities ranging from $4000-7000 \mathrm{~m} / \mathrm{s}$ [Guégen and Palciauskas, 1994]. These values coincide well with the synthetic aggregates when the muscovite content is low (Figure 14). Most of the synthetic samples have $V_{\mathrm{P}} / \mathrm{V}_{\mathrm{S}}$ ratios lower than 1.7 , due to the high initial porosity. A consequence of the UCP and crystallographic preferred orientation, identified in both measured and modeled data, is the variation in $\mathrm{V}_{\mathrm{P}} / \mathrm{V}_{\mathrm{S}}$ ratio with respect to the orientation of the foliation plane. The $\mathrm{V}_{\mathrm{P} 0} / \mathrm{V}_{\mathrm{S} 0}$ ratio is consistently higher perpendicular to the axis of compression, with differences up to $0.05-0.15$ from parallel to the compression axis. Our results highlight that $\mathrm{V}_{\mathrm{P}} / \mathrm{V}_{\mathrm{S}}$ is anisotropic, and is affected by composition, texture intensity and porosity, which is significant since this ratio is often used to separate lithologies [e.g., Mavko et al., 2009].

\section{Conclusions}

[34] Seismic velocities have been measured and calculated from texture data for a set of synthetic calcite-muscovite aggregates. Velocities in the synthetic calcite-muscovite aggregates are comparable to calcite-bearing rocks with a granular petrographic framework [Anselmetti and Eberli, 1993], but are significantly different from low-porosity crystalline rocks, such as marbles or mylonites. We have shown that velocities obtained for samples with no or small muscovite contents compare reasonably well with published values for calcite and lithified carbonates.
[35] Three factors have been shown to influence the measured and modeled data. These are 1) the ratio of calcite to muscovite, 2) the initial porosity of the samples subsequent to hot pressing and 3) the applied load during coldpressing of the samples. In addition, it is likely that the elastic properties of the synthetic aggregates are controlled to some extent by the matrix framework, such as the particular grain-shapes of calcite and muscovite and grainboundary contacts, although we have not been able to quantify this effect. Seismic anisotropy in the calcitemuscovite aggregates increases systematically with increasing muscovite content and applied cold-pressing load. Samples with muscovite contents $>5 \%$ are clearly affected by the increased amount of porosity, even when the confining pressure reaches $400 \mathrm{MPa}$. $\mathrm{P}$ waves display greater differences for measured and calculated velocities, compared to the $\mathrm{S}$-waves. The reduced $\mathrm{P}$ wave velocities result from their dependence on the bulk modulus, which in turn is dependent on the porosity and granular-type framework of the aggregates; the bulk modulus is more affected by porosity and matrix framework than the shear modulus.

[36] Measured seismic anisotropies are consistently lower than velocities calculated from textures. The texture derived elastic properties must be considered, particularly when a medium is known to be anisotropic, but this may not be sufficient to explain elastic properties in materials with cracks or micro-porosity, containing air, gas or pore fluids (or a mixture of these). However, model velocities based on texture and single-crystal elastic constants serve as a basis for building more extensive models, which consider pores, pore fluids and other matrix related factors. We have demonstrated that a good agreement between measured and calculated velocities can be found when accounting for the initial porosity of the synthetic aggregates, using a differential effective medium model.

[37] Acknowledgments. The work presented here is supported by the Swiss national science foundation grant 2-77070-07. We would like to thank two anonymous reviewers for their valuable comments and suggestions, which helped to improve the manuscript. Robert Hoffman provided technical assistance with laboratory equipment.

\section{References}

Aleksandrov, K. S., and T. V. Ryzhova (1961a), The elastic properties of crystals, Sov. Phys. Crystallogr., 6, 228-252.

Aleksandrov, K. S., and T. V. Ryzhova (1961b), Elastic properties of rockforming minerals, part II. Layered silicates, Izv. Acad. Sci. USSR Phys. Solid Earth, 12, 1165-1168.

Anderson, D. L., B. Minster, and D. Cole (1974), The effect of oriented cracks on seismic velocities, J. Geophys. Res., 79, 4011-4015, doi:10.1029/JB079i026p04011.

Anselmetti, F. S., and G. P. Eberli (1993), Controls on sonic velocity in carbonates, Pure Appl. Geophys., 141, 287-323, doi:10.1007/BF00998333.

Anselmetti, F. S., G. A. Von Salis, K. J. Cunningham, and G. P. Eberli (1997), Acoustic properties of Neogene carbonates and siliciclastics from the sub-surface of the Florida Keys: Implications for seismic reflectivity, Mar. Geol., 144, 9-31, doi:10.1016/S0025-3227(97)00081-9.

Austin, N., B. Evans, M. Herwegh, and A. Ebert (2008), Strain localization in the Morcles Nappe (Helvetic Alps, Switzerland), Swiss J. Geosci., 101, 341-360, doi:10.1007/s00015-008-1264-2.

Bayuk, I. O., M. Ammerman, and E. M. Chesnokov (2007), Elastic moduli of anistropic clay, Geophysics, 72, D107-D117, doi:10.1190/1.2757624.

Bernabé, Y., D. T. Fryer, and J. A. Hayes (1992), The effect of cement on the strength of granular rocks, Geophys. Res. Lett., 19, 1511-1514, doi:10.1029/92GL01288. 
Berryman, J. G. (1995), Mixture theories for rock properties, in A Handbook of Physical Constants, edited by T. J. Ahrens, pp. 205-228, AGU, Washington, D. C.

Birch, F. (1960), The velocity of compressional waves in rocks to 10 kilobars, Part 1, J. Geophys. Res., 65, 1083-1102, doi:10.1029/ JZ065i004p01083.

Bunge, H.-J. (1982), Texture Analysis in Materials Science, 593 pp., Butterworths, London.

Burlini, L., and D. M. Fountain (1993), Seismic anisotropy of metapelites from the Ivrea-Verbano zone and Serie dei Laghi (northern Italy), Phys. Earth Planet. Inter., 78, 301-317, doi:10.1016/0031-9201(93)90162-3.

Burlini, L., and K. Kunze (2000), Fabric and seismic properties of Carrara marble mylonites, Phys. Chem. Earth, 25, 133-139, doi:10.1016/S14641895(00)00022-3.

Burlini, L., D. Marquer, N. Challandes, S. Mazzola, and N. Zangarini (1998), Seismic properties of highly strained marbles from the Splügenpass, central Alps, J. Struct. Geol., 20, 277-292, doi:10.1016/ S0191-8141(97)00084-9.

Carlson, R. L., and N. I. Christensen (1979), Velocity anisotropy in semiindurated calcareous deep sea sediments, J. Geophys. Res., 84, 205-211, doi:10.1029/JB084iB01p00205.

Carlson, R. L., C. H. Schaftenaar, and R. P. Moore (1984), Causes of compressional-wave anisotropy in carbonate-bearing, deep-sea sediments, Geophysics, 49, 525-532, doi:10.1190/1.1441688.

Casey, M. (1981), Numerical analysis of X-ray texture data: An implementation in FORTRAN allowing triclinic or axial specimen symmetry and most crystal symmetries, Tectonophysics, 78, 51-64, doi:10.1016/00401951(81)90005-6.

Cheeney, R. F. (1983), Statistical Methods in Geology, 169 pp., Allen and Unwin, London.

Chen, C.-C., C.-C. Lin, L.-G. Liu, S. V. Sinogeikin, and J. D. Bass (2001), Elasticity of single-crystal calcite and rhodochrosite by Brillouin spectroscopy, Am. Mineral., 86, 1525-1529.

Cholach, P. Y., and D. R. Schmitt (2006), Intrinsic elasticity of a textured transversely isotropic muscovite aggregate: Comparisons to the seismic anisotropy of schists and shales, J. Geophys. Res., 111, B09410, doi:10.1029/2005JB004158.

Crawford, B. R., D. R. Faulkner, and E. H. Rutter (2008), Strength, porosity, and permeability development during hydrostatic and shear loading of synthetic quartz-clay fault gouge, J. Geophys. Res., 113, B03207, doi:10.1029/2006JB004634.

Dandekar, D. P. (1968), Pressure dependence of the elastic constants of calcite, Phys. Rev., 172, 873-877, doi:10.1103/PhysRev.172.873.

Den Brok, S. W. J., C. David, and Y. Bernabé (1997), Preparation of synthetic sandstones with variable cementation for studying the physical properties of granular rocks, C. R. Acad. Sci. Ser. IIa Sci. Terre Planetes, $325,487-492$

Dvorkin, J., G. Mavko, and A. Nur (1991), The effect of cementation on the elastic properties of granular material, Mech. Mater., 12, 207-217, doi:10.1016/0167-6636(91)90018-U.

Dvorkin, J., A. Nur, and H. Yin (1994), Effective properties of cemented granular materials, Mech. Mater., 18, 351-366, doi:10.1016/0167-6636 (94)90044-2.

Ellis, D., J. Howard, C. Flaum, D. McKeon, H. Scott, O. Serra, and G. Simmons (1988), Mineral logging parameters: Nuclear and acoustic, Technol. Rev., 36, 38-55.

Eshelby, J. D. (1957), The determination of the elastic field of an ellipsoidal inclusion, and related problems, Proc. R. Soc. London Ser. A, 241, 376-396, doi:10.1098/rspa.1957.0133.

Gautam, R., and R. C. K. Wong (2006), Transversely isotropic stiffness parameters and their measurements in Colorado shale, Can. Geotech. J., 43, 1290-1305, doi:10.1139/T06-083.

Guégen, Y., and V. Palciauskas (1994), Introduction to the Physics of Rocks, 294 pp., Princeton Univ. Press, Princeton, N. J.

Hill, R. (1952), The elastic behavior of a crystalline aggregate, Proc. Phys. Soc. London Sect. A, 65, 349-354, doi:10.1088/0370-1298/65/5/307.

Hornby, B. E. (1998), Experimental laboratory determination of the dynamic elastic properties of wet, drained shales, J. Geophys. Res., 103, 29,945-29,964, doi:10.1029/97JB02380.

Hornby, B. E., L. M. Schwartz, and J. A. Hudson (1994), Anisotropic effective-medium modeling of the elastic properties of shales, Geophysics, 59, 1570-1583, doi:10.1190/1.1443546.

Johnston, J. E., and N. I. Christensen (1995), Seismic anisotropy of shales, J. Geophys. Res., 100, 5991-6003, doi:10.1029/95JB00031.

Jones, C., and P. G. Meredith (1998), An experimental study of elastic wave propagation anisotropy and permeability anisotropy in illitic shale, paper presented at EUROCK '98 Rock Mechanics in Petroleum Engineering, Soc. of Pet. Eng., Int. Soc. for Rock Mech., Trondheim, Norway, 8-10 Jul.
Jones, T. D., and A. Nur (1984), The nature of seismic reflections from deep crustal fault zones, J. Geophys. Res., 89, 3153-3171, doi:10.1029/ JB089iB05p03153

Kennedy, L. A., and J. C. White (2001), Low-temperature recrystallization in calcite: Mechanisms and consequences, Geology, 29, 1027-1030, doi:10.1130/0091-7613(2001)029<1027:LTRICM>2.0.CO;2.

Kern, H. (1990), Laboratory seismic measurements: An aid in the interpretation of seismic field data, Terra Nova, 2, 617-628, doi:10.1111/j.13653121.1990.tb00127.x.

Khazanehdari, J., E. H. Rutter, M. Casey, and L. Burlini (1998), The role of crystallographic fabric in the generation of seismic anisotropy and reflectivity of high strain zones in calcite rocks, J. Struct. Geol., 20, 293-299, doi:10.1016/S0191-8141(97)00061-8

Lapierre, J., D. Mainprice, and W. Ben Ismail (1996), Calculation of rock properties from pole figures using LabView, in Structural Geology and Personal Computers, edited by D. G. DePaor, pp. 167-178, doi:10.1016/S1874-561X(96)80015-0, Pergamon, Oxford, U. K.

Leiss, B., and K. Ullemeyer (1999), Texture characterisation of carbonate rocks and some implications for the modeling of physical anisotropies, derived from idealized texture types, Z. Dtsch. Geol. Ges., 150, 259-274.

Mainprice, D. (1990), A FORTRAN program to calculate seismic anisotropy from the lattice preferred orientation of minerals, Comput. Geosci., 16, 385-393, doi:10.1016/0098-3004(90)90072-2.

Mainprice, D. (1997), Modeling the anisotropic seismic properties of partially molten rocks found at mid-ocean ridges, Tectonophysics, 279, 161-179, doi:10.1016/S0040-1951(97)00122-4.

Mainprice, D. (2007), Seismic anisotropy of the deep Earth from a mineral and rock physics perspective, in Treatise on Geophysics, vol. 2, edited by G. Schubert, pp. 437-491, Elsevier, Amsterdam.

Mainprice, D., and M. Humbert (1994), Methods of calculating petrophysical properties from lattice preferred orientation data, Surv. Geophys., 15, 575-592, doi:10.1007/BF00690175.

Mainprice, D., J.-L. Bouchez, M. Casey, and J. Dervin (1993), Quantitative texture analysis of naturally deformed anhydrite by neutron diffraction texture goniometry, J. Struct. Geol., 15, 793-804, doi:10.1016/01918141(93)90063-G.

Marion, D., A. Nur, H. Yin, and D. Han (1992), Compressional velocity and porosity in sand-clay mixtures, Geophysics, 57, 554-563, doi:10.1190/1.1443269.

Mavko, G., T. Mukerji, and J. Dvorkin (2009), The Rock Physics Handbook, 511 pp., doi:10.1017/CBO9780511626753, Cambridge Univ. Press, Cambridge, U. K.

Mondol, N. H., K. Bjørlykke, J. Jahren, and K. Høeg (2007), Experimental mechanical compaction of clay mineral aggregates - Changes in physical properties of mudstone during burial, Mar. Pet. Geol., 24, 289-311, doi:10.1016/j.marpetgeo.2007.03.006.

Nishizawa, O., and T. Yoshino (2001), Seismic velocity anisotropy in mica-rich rocks: An inclusion model, Geophys. J. Int., 145, 19-32, doi:10.1111/j.1365-246X.2001.00331.x.

Nur, A., and G. Simmons (1969), The effect of saturation on velocity in low-porosity rocks, Earth Planet. Sci. Lett., 7, 183-193, doi:10.1016/ 0012-821X(69)90035-1.

Peselnick, L., and R. A. Robie (1963), Elastic constants of calcite, J. Appl. Phys., 34, 2494-2495, doi:10.1063/1.1702777.

Rafavich, F., C. H. S. C. Kendall, and T. P. Todd (1984), The relationship between acoustic properties and the petrographic character of carbonate rocks, Geophysics, 49, 1622-1636, doi:10.1190/1.1441570.

Reuss, A. (1929), Berechnung der fliessgrenze von mischkristallen aufgrund der plastizitätsbedingung für einkristalle, Z. Angew. Math. Mech., 9, 49-58, doi:10.1002/zamm.19290090104.

Sarout, J., and Y. Guéguen (2008a), Anisotropy of elastic wave velocities in deformed shales: Part 1-Experimental results, Geophysics, 73, D75-D89, doi:10.1190/1.2952744.

Sarout, J., and Y. Guéguen (2008b), Anisotropy of elastic wave velocities in deformed shales: Part 2-Modeling results, Geophysics, 73, D91-D103, doi:10.1190/1.2952745

Sayers, C. M. (2005), Seismic anisotropy of shales, Geophys. Prospect., 53, 667-676, doi:10.1111/j.1365-2478.2005.00495.x.

Schmidt, V., L. Burlini, A. M. Hirt, and B. Leiss (2008), Fabrication of synthetic calcite-muscovite rocks with variable texture-An analogue to cataclasite fabrics? Tectonophysics, 449, 105-119, doi:10.1016/j. tecto.2007.11.055.

Schmidt, V., A. M. Hirt, B. Leiss, L. Burlini, and J. M. Walter (2009), Quantitative correlation of texture and magnetic anisotropy of compacted calcite-muscovite aggregates, J. Struct. Geol., doi:10.1016/j. jsg.2008.11.012.

Siegesmund, S., and H. Kern (1990), Velocity anisotropy and shear-wave splitting in rocks from the mylonite belt along the Insubric line (Ivrea 
Zone, Italy), Earth Planet. Sci. Lett., 99, 29-47, doi:10.1016/0012-821X (90)90068-9.

Takanashi, M., O. Nishizawa, K. Kanagawa, and K. Yasunaga (2001), Laboratory measurements of elastic anisotropy parameters for the exposed crustal rocks from the Hidaka metamorphic belt, central Hokkaido, Japan, Geophys. J. Int., 145, 33-47, doi:10.1111/j.1365246X.2001.00332.x.

Thomsen, L. (1986), Weak elastic anisotropy, Geophysics, 51, 1954-1966, doi:10.1190/1.1442051.

Ulm, F.-J., and Y. Abousleiman (2006), The nanogranular nature of shale, Acta Geotech., 1, 77-88, doi:10.1007/s11440-006-0009-5.

Valcke, S. L. A., M. Casey, G. E. Lloyd, J.-M. Kendall, and Q. J. Fischer (2006), Lattice preferred orientation and seismic anisotropy in sedimentary rocks, Geophys. J. Int., 166, 652-666, doi:10.1111/j.1365246X.2006.02987.x.

Vaughan, M. T., and S. Guggenheim (1986), Elasticity of muscovite and its relationship to crystal structure, J. Geophys. Res., 91, 4657-4664, doi:10.1029/JB091iB05p04657.

Verwer, K., H. Braaksma, and J. A. M. Kenter (2008), Acoustic properties of carbonates: Effects of rock texture and implications for fluid substitution, Geophysics, 73, B51-B65, doi:10.1190/1.2831935.

Voigt, W. (1928), Lehrbuch der Kristallphysik, 978 pp., Teubner, Leipzig, Germany.

Voltolini, M., H.-R. Wenk, N. H. Mondol, K. Bjørlykke, and J. Jahren (2009), Anisotropy of experimentally compressed kaolinite-illite-quartz mixtures, Geophysics, 74, D13-D23, doi:10.1190/1.3002557.

Walsh, J. B. (1965), The effect of cracks on the compressibility of rock, J. Geophys. Res., 18, 429-435.
Wang, Z. (1997), Seismic properties of carbonate rocks, in Carbonate Seismology, edited by I. Palaz and K. J. Marfurt, pp. 29-52, Soc. of Explor. Geophys., Tulsa, Okla.

Wang, Z., W. K. Hirsche, and G. Sedgwick (1991), Seismic velocities in carbonate rocks, J. Can. Pet. Technol., 30, 112-122.

Weiss, T., S. Siegesmund, W. Rabbel, T. Bohlen, and M. Pohl (1999), Seismic velocities and anisotropy of the lower continental crust: A review, Pure Appl. Geophys., 156, 97-122, doi:10.1007/s000240050291.

Wenk, H.-R., M. Voltolini, H. Kern, T. Popp, and M. Mazurek (2008), Anisotropy in shale from Mont Terri, Lead. Edge, 27, 742-748, doi:10.1190/1.2944161.

Wepfer, W. W., and N. I. Christensen (1991), A seismic velocity confining pressure relation, with applications, Int. J. Rock Mech. Min. Sci. Geomech. Abstr., 28, 451-456, doi:10.1016/0148-9062(91)90083-X

Wong, R. C. K., D. R. Schmitt, D. Collis, and R. Gautam (2008), Inherent transversely isotropic elastic parameters of over-consolidated shale measured by ultrasonic waves and their comparison with static and acoustic in situ log measurements, J. Geophys. Eng., 5, 103-117, doi:10.1088/ $1742-2132 / 5 / 1 / 011$

B. S. G. Almqvist and A. M. Hirt, Institute of Geophysics, ETH Zurich, Schafmattstr. 30, CH-8093 Zurich, Switzerland. (bjarne.almqvist@mag.ig. erdw.ethz.ch)

L. Burlini, Geological Institute, ETH Zurich, Leonhardstr. 19, CH-8092 Zurich, Switzerland

D. Mainprice, Géosciences Montpellier, Université Montpellier 2, Place Eugène Bataillon, F-34095 Montpellier, France. 